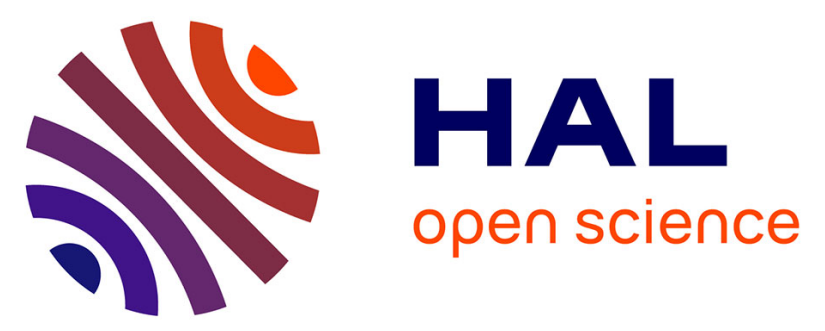

\title{
Size distribution time series of a polar stratospheric cloud observed above Arctic Lidar Observatory for Middle Atmosphere Research (ALOMAR) $\left(69^{\circ} \mathrm{N}\right)$ and analyzed from multiwavelength lidar measurements during winter 2005
}

Julien Jumelet, Slimane Bekki, Christine David, Philippe Keckhut, G. Baumgarten

\section{- To cite this version:}

Julien Jumelet, Slimane Bekki, Christine David, Philippe Keckhut, G. Baumgarten. Size distribution time series of a polar stratospheric cloud observed above Arctic Lidar Observatory for Middle Atmosphere Research (ALOMAR) $\left(69^{\circ} \mathrm{N}\right)$ and analyzed from multiwavelength lidar measurements during winter 2005. Journal of Geophysical Research: Atmospheres, 2009, 114, pp.D02202. 10.1029/2008JD010119 . hal-00355219

\author{
HAL Id: hal-00355219 \\ https://hal.science/hal-00355219
}

Submitted on 28 Feb 2016

HAL is a multi-disciplinary open access archive for the deposit and dissemination of scientific research documents, whether they are published or not. The documents may come from teaching and research institutions in France or abroad, or from public or private research centers.
L'archive ouverte pluridisciplinaire HAL, est destinée au dépôt et à la diffusion de documents scientifiques de niveau recherche, publiés ou non, émanant des établissements d'enseignement et de recherche français ou étrangers, des laboratoires publics ou privés. 


\title{
Size distribution time series of a polar stratospheric cloud observed above Arctic Lidar Observatory for Middle Atmosphere Research (ALOMAR) $\left(69^{\circ} \mathrm{N}\right)$ and analyzed from multiwavelength lidar measurements during winter 2005
}

\author{
Julien Jumelet, ${ }^{1}$ Slimane Bekki, ${ }^{1}$ Christine David, ${ }^{1}$ Philippe Keckhut, ${ }^{1}$ and Gerd Baumgarten ${ }^{2}$ \\ Received 13 March 2008; revised 3 November 2008; accepted 17 November 2008; published 22 January 2009.
}

[1] A case study of a polar stratospheric cloud (PSC) is described using multiwavelength $(355,532$, and $1064 \mathrm{~nm})$ lidar measurements performed at the Arctic Lidar Observatory for Middle Atmosphere Research (ALOMAR) on 6 December 2005. Rotational Raman signals at 529 and $530 \mathrm{~nm}$ are used to derive a temperature field within the cloud using the rotational Raman technique (RRT). The PSC size distributions are retrieved between 1500 and 2000 UTC through a combination of statistical filtering and best match approaches. Several PSC types were detected between 22 and $26 \mathrm{~km}$ during the measurement session. Liquid ternary aerosols are identified before about 1600 and after 1900 UTC typically; their averaged retrieved size distribution parameters and associated errors at the backscatter peak are: $\mathrm{N}_{\mathrm{o}} \approx 1-10 \mathrm{~cm}^{-3}(50 \%), \mathrm{r}_{\mathrm{m}} \approx 0.15 \mu \mathrm{m}$ (20\%), and $\sigma \approx 1.2(15 \%)$. A mode of much larger particles is detected between 1600 and 1900 UTC $\left(\mathrm{N}_{\mathrm{o}} \approx 0.04 \mathrm{~cm}^{-3}(30 \%), \mathrm{r}_{\mathrm{m}} \approx 1.50 \mu \mathrm{m}(15 \%)\right.$, and $\sigma \approx 1.37(10 \%)$. The different PSC types are also identified using standard semiempirical classifications, based on lidar backscatter, temperature, and depolarization. Overall, the characteristics of the retrieved size distributions are consistent with these classifications. They all suggest that these very large particles are certainly nitric acid trihydrate that could have been generated by the strong gravity wave activity visible in the temperature profiles. The results demonstrate that multiwavelength lidar data coupled to both RRT temperatures and our size distribution retrieval can provide useful additional information for identification of PSC types and for direct comparisons with microphysical model simulations.

Citation: Jumelet, J., S. Bekki, C. David, P. Keckhut, and G. Baumgarten (2009), Size distribution time series of a polar stratospheric cloud observed above Arctic Lidar Observatory for Middle Atmosphere Research (ALOMAR) $\left(69^{\circ} \mathrm{N}\right)$ and analyzed from multiwavelength lidar measurements during winter 2005, J. Geophys. Res., 114, D02202, doi:10.1029/2008JD010119.

\section{Introduction}

[2] Polar stratospheric clouds (PSC) are mainly composed of water and nitric acid. Their formation is a key step in the chain of events leading to the destruction of ozone in the lower polar stratosphere during the spring. PSC are responsible for chlorine activation (i.e., conversion of inorganic chlorine and bromine reservoir species into reactive ozone-destroying radicals) through heterogeneous chemistry. Because of their gravitational sedimentation, they are also responsible for the denitrification of the polar lower stratosphere that prevents chlorine deactivation, the activation reverse process, and hence favors the ozone destruction [World Meteorological Organization, 2007].

[3] PSC are actually split into three main types, according to their composition. Liquid solution droplets of water

\footnotetext{
${ }^{1}$ Service d'Aéronomie, IPSL, UPMC, CNRS, Paris, France.

${ }^{2}$ Leibniz-Institut für Atmosphärenphysik, Kühlungsborn, Germany.
}

Copyright 2009 by the American Geophysical Union. 0148-0227/09/2008JD010119 vapor, nitric acid and sulphuric acid are known as liquid ternary aerosols (LTA or type Ib PSC) with typical median radii $\mathrm{r}_{\mathrm{m}}$ of around $0.3 \mu \mathrm{m}$ and number densities $\mathrm{N}_{\mathrm{o}}$ of around $10 \mathrm{~cm}^{-3}$ [Tabazadeh et al., 1994; Carslaw et al., 1994]. Solid nitric acid trihydrate (NAT) particles are usually larger than LTA with radius on the order of $1 \mu \mathrm{m}$ and concentrations on the order of $10^{-2} \mathrm{~cm}^{-3}$ [Voigt et al., 2000]. Nonetheless, there might be case of NAT PSC with particle size of several $\mu \mathrm{m}$, the so-called NAT-Rock [Fahey et al., 2001] or with sizes more typical of LTA and enhanced NAT number densities around $\mathrm{N}_{\mathrm{o}}>0.1 \mathrm{~cm}^{-3}$ [Tsias et al., 1999]. Ice particles are known as type II PSC [Goodman et al., 1989]. Although the temperature threshold of STS particles is below the NAT temperature threshold, LTA are commonly observed because there are energy barriers for NAT and ice nucleation [Tabazadeh et al., 1994]. The stability of NAT [Hanson and Mauersberger, 1988] and its subsequent effects on chlorine activation and denitrification of the polar stratosphere are well established [Popp et al., 2001; World Meteorological Organization, 2007]. However, there are still uncertainties on the NAT formation 
processes [Toon et al., 2000] with several formation mechanisms being put forward such as homogeneous nucleation in ternary solutions [Knopf et al., 2002], heterogeneous nucleation on ice [Carslaw et al., 1998; Luo et al., 2003] or on other condensation nuclei like meteoritic dust particles [Drdla, 1996; Peter, 1997; Voigt et al., 2005]. Energy barriers may often prevent NAT particles from reaching their equilibrium volume and PSC containing a majority of LTA also often contain nonequilibrated hydrate particles [Shibata et al., 1999a, 1999b]. Biele et al. [2001] suggested that PSC microphysics is more often characterized by nonequilibrium conditions than assumed previously.

[4] The rate of heterogeneous reactions on PSC can differ considerably on solid and liquid particles. It depends on the particle chemical composition and on size-related quantities, typically the total surface area density (A) and/or volume concentration (V), both being calculated from the PSC size distribution. Also, the rate of gravitational sedimentation is strongly dependent on the higher moments of the PSC size distribution. Therefore, it is necessary to determine accurately PSC size distribution and, in particular, the large size tail of this distribution in order to calculate the PSC-related process rates. However, measurements of PSC size distributions are very rare, the most common being balloon-borne in situ measurements such as optical particle counter measurements [Deshler et al., 2003a]. There are also remote measurements of PSC optical properties such as extinction or backscatter, either accessible from satellite or lidar soundings; these measurements do not give directly the size distribution because the optical properties are integrated over the entire size distribution. The present paper focuses on lidar measurements that have often been used to identify different types of PSC according to classifications [Browell et al., 1990; David et al., 1997].

[5] Retrieving particle optical properties from lidar signals requires several assumptions: a reference altitude in the aerosol free air at the top of the altitude range and, more importantly, a relationship between the extinction and backscatter, expressed as the ratio of the backscatter to extinction (lidar ratio) [Klett, 1981, 1985]. The determination of the backscatter requires knowledge of this lidar ratio. In most studies, the value of the lidar ratio is assumed to be constant.

[6] One of the most interesting developments in aerosol lidar measurements is the addition of Raman channels. The lidar inversion using Raman lidar measurements does not require any assumption on the value of the lidar ratio. As the inelastic Raman backscattered signal is only affected by particle extinction and not by the scattering, the particle extinction can be determined independently from the backscatter [Ansmann et al., 1990]. Direct determination of the particle size distribution from uniwavelength lidar measurements is however theoretically precluded because of a lack of constraints [Müller and Quenzel, 1985]. Size characterization of particles has now been made possible and accurate with multiwavelength Raman lidar [Müller et al., 1998; Veselovskii et al., 2002]. In addition, this size distribution retrieval inverse problem remains highly nonlinear. This type of inversion problem is often solved using regularization techniques. But an accurate retrieval requires numerous constraints under the form of extensive data sets of measured backscatter and extinction coefficients. With enough constraints, regularization techniques also enable the determination of the refractive index [Veselovskii et al., 2004].

[7] In the stratosphere, the particle extinction is measured with a limited accuracy. In addition, most of the best equipped lidar stations only monitor the stratosphere at three wavelengths, typically at 355, 532 and $1064 \mathrm{~nm}$. Because of these two limitations, the regularization technique is not necessarily the most suited approach for retrieving stratospheric particle size distributions from lidar data. A semiempirical approach to retrieve the particle size distribution from three commonly measured particle backscatter has recently been developed and validated [Jumelet et al., 2008]. This size distribution retrieval method was inspired by the works of Beyerle et al. [1994], and Mehrtens et al. [1999]. It is based on comparing measured and simulated lidar backscatter coefficients. The retrieval algorithm minimizes a cost function of the misfit between lidar measurements and model simulations (look-up table) with the control variables being the parameters of the PSC size distribution. The errors on the measurements are explicitly taken into account in the search for a solution. A clusterbased filtering of the solution pool ensures both stability and reliable error estimation. The method and its validation will be briefly described in section 3.3. Differences with the works of Beyerle et al. [1994] and Mehrtens et al. [1999] are threefold: First, in our retrieval algorithm, the particle refractive index is not specified but calculated from the modeled equilibrium particle chemical composition. Second, we use a statistical filtering to account for the nonlinearities of the optical model (see section 3.3). Third, this methodology has been validated against both independent size distribution measurements [Jumelet et al., 2008].

[8] Besides the capability to estimate the particle extinction, Raman lidar measurements allow for temperature retrieval at high vertical resolution (300 $\mathrm{m}$ or less) through the rotational Raman technique (hereafter referred as RRT). Temperature is important in the size distribution retrieval algorithm because the refractive index required in the optical module is derived from equilibrium composition calculations that are very sensitive to temperature. Temperature is also the key factor controlling PSC formation. The Arctic vortex is less stable and cold than the Antarctic vortex with temperatures tending to be marginally below PSC temperature thresholds. Temperature variations caused by small-scale processes such as orographically induced gravity waves are important because they can trigger PSC formation especially in the Arctic, despite large-scale temperatures being above PSC temperature thresholds [Meilinger et al., 1995; Dornbrack et al., 2002; Lowe et al., 2006; Eckermann et al., 2006]. Gravity waves are easily detected in time series of RRT temperature profiles and are often observed above the Arctic Lidar Observatory for Middle Atmosphere Research (ALOMAR), Andenes, Norway [Schöch, 2007]. Despite their local influence, mountain wave PSC may lead to significant ozone loss in the polar vortex [Carslaw et al., 1998; Dornbrack et al., 2001; Dornbrack and Leutbecher, 2001; Fueglistaler et al., 2003; Kühl et al., 2004].

[9] This paper is a case study of a PSC event observed above ALOMAR, on 6 December 2005. PSC size distributions are retrieved from lidar backscatter data and the results 
compared to classical approaches of PSC characterization. The lidar inversion is performed on relatively short time intervals in order to preserve as much as possible of the temporal variability in the analysis. As a result, the lidar errors are larger than typical errors associated to longer lidar integration times. The retrieved size parameters are correlated with RRT temperature, air mass trajectories and lidar measurements in order to check that the retrieved size distribution parameters are consistent with our knowledge of PSC. This consistency provides an additional validation of the size distribution retrieval algorithm.

[10] It is worth pointing out that lidar observations above a single station are rather limited in providing information on the microphysical evolution of a PSC cloud. Ideally, one would like to probe the moving air mass where the cloud forms along its trajectory. This may certainly be possible by coupling different lidar stations according to a Lagrangian approach, when the same air mass is probed above different lidar stations. The same approach, the so-called "Match" technique, has already been applied successfully to infer chemical ozone loss from analysis of balloon soundings pairs measuring ozone in the same air mass at different points of a trajectory [Rex et al., 1998, 1999]. This approach is being applied to the study of PSC microphysical evolution during a Lagrangian campaign, called "MATCH PSC," within the framework of the International Polar Year project ORACLE-O 3 (see http://classic.ipy.org/development/ framework/index.htm).

\section{Measurements}

\subsection{Lidar Inversion}

[11] The PSC event was detected above ALOMAR where lidar measurements are performed routinely. The ALOMAR RMR lidar, located at $69^{\circ} \mathrm{N} / 16^{\circ} \mathrm{E}$ near Andøya, emits laser pulses at 355,532 and $1064 \mathrm{~nm}$. The beam is produced by a $30-\mathrm{Hz}$ repetition rate pulsed $\mathrm{Nd}-\mathrm{YAG}$ twin laser. The backscattered light is received on 180-cm-diameter Cassegrain telescopes with a field-of-view of $180 \mu \mathrm{rad}$ and detected with photomultiplier tubes in photo-counting mode [von Zahn et al., 2000]. The vibrational Raman measurements at 387 and $607 \mathrm{~nm}$ (associated to the 355 and $532 \mathrm{~nm}$ wavelengths respectively) and the rotational Raman measurements at 529 and $530 \mathrm{~nm}$ are also performed simultaneously. Our lidar inversion algorithm takes full advantage of the Raman detection. The backscatter coefficients at 355 and $532 \mathrm{~nm}$ are retrieved using the inelastic Raman $\mathrm{N}_{2}$-scattering detected at 387 and $607 \mathrm{~nm}$ respectively, which provide independent particle extinction profiles and an estimate of the lidar ratio [Ansmann et al., 1990]. There is thus no assumption on the value of the lidar ratio (extinction over scattering) in the inversion of the lidar equation, linking the received signal and the backscatter. The lidar inversion also requires the choice of a reference altitude at which the backscatter is purely molecular (no particles) and therefore can be used to normalize the signal. The reference altitude is taken above the top of the PSC layer that is typically in the $28-32 \mathrm{~km}$ range. The backscatter at $1064 \mathrm{~nm}$ is retrieved with the Klett method using the lidar ratio value derived at $532 \mathrm{~nm}$ because there is no Raman detection at $1064 \mathrm{~nm}$. At this wavelength, where the atmospheric transmission effect is small, the critical parameter is not the lidar ratio but the reference altitude [Ansmann et al., 1990].

[12] The ALOMAR RMR lidar is also able to detect the backscattered light at rotational Raman wavelengths (529 and $530 \mathrm{~nm}$ ). The amplitudes of the two Stoke and antiStoke wings of the rotational Raman spectrum associated to nitrogen scattering are temperature-dependent and this relationship can be approximated with an analytical expression [Cooney and Pina, 1976; Nedeljkovic et al., 1993; Behrendt and Reichardt, 2000]. Once calibrated with a reference temperature data set, this expression allows retrieving the temperature (see section 2.3). Since the RRT temperature has the same spatial and temporal resolution as the lidar measurement, it is used for the determination of the Rayleigh contribution (molecular scattering) in the lidar inversion process.

[13] Overall, the combined use of rotational and vibrational Raman wavelengths results in lower errors in the determination of the backscatter via the input of more accurate values of temperatures and lidar ratios in the lidar inversion [Ansmann et al., 1990, 1992a, 1992b]. As shown later, the retrieval of the particle size distribution relies for an important part on the quality of the lidar inversion. The lower the errors on the backscatter, the more reliable the retrieved particle size distributions.

\subsection{Backscatter Coefficients}

[14] The particle backscatter coefficient $\beta_{\text {Par }}$ (hereafter referred as $\beta)\left(\mathrm{m}^{-1} \mathrm{sr}^{-1}\right)$ is expressed as

$$
\beta_{\text {Par }}=\int_{0}^{\infty} \mathrm{n}(\mathrm{r}) \frac{d \sigma_{b}}{d \Omega}(r, \lambda, m) d r
$$

where $\lambda$ is the incident wavelength, $n(r)$ is the number of particles at the radius $\mathrm{r}$ between $\mathrm{r}$ and $\mathrm{r}+\mathrm{dr}$ (the size distribution), $m$ the refractive index and $\mathrm{d} \sigma_{\mathrm{b}} / \mathrm{d} \Omega$ the particle backscattering differential cross section. The $\beta_{\text {Par }}$ at $355 \mathrm{~nm}$ and $532 \mathrm{~nm}$ are calculated using the extinction calculated from the vibrational Raman wavelengths $387 \mathrm{~nm}$ and $607 \mathrm{~nm}$, respectively, according to the lidar Raman equation as described by Ansmann et al. [1990]. An expression of the lidar backscatter ratio $\mathrm{R}$ can be derived from the ratio between the elastic and inelastic lidar signals,

$$
R(z)=\frac{\beta_{\text {Par }}(z)+\beta_{\text {Ray }}(z)}{\beta_{\text {Ray }}(z)}=\frac{P_{\lambda}(z) \times P_{\lambda_{R}}\left(z_{0}\right)}{P_{\lambda}\left(z_{0}\right) \times P_{\lambda_{R}}(z)},
$$

where $\mathrm{P} \lambda(\mathrm{z})$ is the received lidar signal at wavelength $\lambda, \lambda_{\mathrm{R}}$ the associated Raman wavelength, $z_{0}$ a reference altitude chosen so that $\beta_{\text {Ray }}\left(\mathrm{z}_{\mathrm{o}}\right) \gg \beta_{\text {Par }}\left(\mathrm{z}_{\mathrm{o}}\right), \beta_{\text {Ray }}$ being the Rayleigh backscatter coefficient. The analytical expression of $\beta_{\mathrm{Par}}$ involves the particle extinction at both $\lambda$ and $\lambda_{\mathrm{R}}$. The fact that the extinction is low in the stratosphere is not a critical problem when determining $\beta_{\text {Par }}$, since the extinction only acts on the return signal as the difference between vibrational Raman and Rayleigh signal extinctions.

[15] The particle backscatter coefficient at $1064 \mathrm{~nm}$ is calculated using the classic Klett method because no Raman scattering is available at this wavelength. The lidar ratio used in this inversion is the one determined at $532 \mathrm{~nm}$, resulting in errors on the backscatter coefficient inferior to 
5\% [Althausen et al., 2000; Wallenhauer, 1998]. The retrieval algorithm also uses the color ratios $\mathrm{CR}_{355 \mathrm{~nm}}$ and $\mathrm{CR}_{1064 \mathrm{~nm}}$, defined with respect to the most sensitive wavelength of the lidar, $532 \mathrm{~nm}$ [Baumgarten et al., 2007],

$$
C R_{\lambda}=\frac{\beta_{P a r}, \lambda}{\beta_{P a r}, 532 \mathrm{~nm}} .
$$

\subsection{RRT Temperature}

[16] Temperature and pressure profiles are required for the calculation of the Rayleigh scattering. Ideally, the temperature and backscatter measurements should be simultaneous. In our case, the rotational Raman channels at $529 \mathrm{~nm}$ and $530 \mathrm{~nm}$ are used to retrieve the temperature profile up to $30 \mathrm{~km}$ using the RRT temperature. It is based on the temperature dependency of the nitrogen and oxygen molecular rotational lines of the Raman spectrum [Cooney and Pina, 1976; Nedeljkovic et al., 1993; Behrendt and Reichardt, 2000]. This dependency can be approximated by the following relation, where $\mathrm{A}$ and $\mathrm{B}$ are to be determined through an alternative reference temperature data set,

$$
T=\frac{A}{B+\log \left(\frac{P_{530 \mathrm{~nm}}}{P_{529 \mathrm{~mm}}}\right)},
$$

where $\mathrm{P}_{530 \mathrm{~nm}}$ and $\mathrm{P}_{529 \mathrm{~nm}}$ are the signals detected at 530 and $529 \mathrm{~nm}$ respectively. Nedeljkovic et al. [1993] estimated the RRT systematic errors at about $1 \mathrm{~K}$, depending on the lidar setup. Total uncertainties on the calculated temperature profiles are directly related to the lidar signal-to-noise ratio and hence, to the data integration time as well as to the calibration. In the case considered here, on 6 December 2005, a PTU (pressure, temperature, humidity) sonde was launched $1 \mathrm{~h}$ before starting the lidar session. The PTU temperature measurements are used as an independent calibration data set. We chose a lidar integration time of $30 \mathrm{~min}$ at $529 \mathrm{~nm}$ and $530 \mathrm{~nm}$ so as to be able to follow the temporal variability of the event. To perform a sensitivity test later on, another lidar data set is created with an integration time of $1 \mathrm{~h}$. The PTU balloon drifted almost $100 \mathrm{~km}$ away from the lidar site at higher altitudes. This drift is taken into account by adjusting the PTU temperature with the temperature difference between the balloon and the lidar positions given by the European Centre for Meteorological Weather Forecasts (ECMWF) analyses. As the reference temperature used for calibration is very close to the PSC lidar measurements both in time and space, the calibration of the RRT should be reliable. The resulting total RRT temperature errors at the PSC altitude are estimated to be around $\pm 2-3 \mathrm{~K}$ for the 30-min-averaged data, dropping to $\pm 1-1.5 \mathrm{~K}$ for the 60 -min-averaged data. It is important to stress that the RRT temperature profiles are used in the lidar inversion algorithm instead of noncoincident balloon measurements or climatological profiles.

\section{Methodology for the Particle Size Distribution Retrieval}

[17] The particle size distribution is retrieved from comparison between measured and simulated backscatter coef- ficients. The stratospheric particle size distribution is assumed to be lognormal and unimodal [Pinnick et al., 1976; World Meteorological Organization, 2006],

$$
n(r)=\frac{N_{0}}{\sqrt{2 \pi} \cdot r \cdot \ln (\sigma)} \times \exp \left(-\frac{\ln ^{2}\left(r / r_{m}\right)}{2 \ln ^{2}(\sigma)}\right),
$$

where $\mathrm{N}_{0}$ is the total number of particles per unit volume and $\sigma$ the geometrical standard deviation (hereafter referred as standard deviation) around the median radius $\mathrm{r}_{\mathrm{m}}$.

[18] In the first phase, the model calculates the chemical composition according to the specific environmental conditions (pressure, temperature, total $\mathrm{HNO}_{3}$, total $\mathrm{H}_{2} \mathrm{O}$ mixing ratios) [Carslaw et al., 1994; Luo et al., 1996] for a range of particle size distributions. The particle range extends from background sulphate aerosols parameters to ice PSC parameters [Jumelet et al., 2008]. In the second phase, a look-up table of $\beta$ as a function of the size distribution parameters is generated. A Mie scattering module [Bohren and Huffman, 1983] is used to calculate the aerosol $\beta$ at different wavelengths (within the visible and near-infrared domain), for each simulated size distribution and chemical composition. This assumes that particles are spherical and so most likely liquid. This hypothesis will be discussed in the last section. In the third phase, the simulated backscatters are compared to the measurements, taking into account the errors on the lidar $\beta$ measurements. The direct model (optical module) is supposed to be perfect (no model errors). For example, the retrieval algorithm does not account for errors in the particle refractive index. A full description and validation of the size distribution estimation is presented by Jumelet et al. [2008].

\subsection{Equilibrium Composition and Refractive Index}

[19] The model calculates the particle composition from a binary $\mathrm{H}_{2} \mathrm{SO}_{4} / \mathrm{H}_{2} \mathrm{O}$ solution to a ternary $\mathrm{H}_{2} \mathrm{SO}_{4} / \mathrm{HNO}_{3} / \mathrm{H}_{2} \mathrm{O}$ (STS) solution [Luo et al., 1996, Krieger et al., 2000]. The aerosol phase is assumed to be in thermodynamical equilibrium with the gas phase. Therefore, in order to determine the particle equilibrium composition (weight fractions in sulphuric acid, nitric acid and water vapor), one needs to solve a set of two nonlinear equations describing the equality between the partial pressures of $\mathrm{HNO}_{3}$ and $\mathrm{H}_{2} \mathrm{O}$ just over the surface of the condensed phase and the partial pressures in the gas phase. The model is initialized with a total (gaseous + condensed) amount of $\mathrm{HNO}_{3}$ and $\mathrm{H}_{2} \mathrm{O}$ and it then redistributes $\mathrm{HNO}_{3}$ and $\mathrm{H}_{2} \mathrm{O}$ between the gas and the condensed phases according to the calculated particle composition. The iterative procedure of the equilibrium composition calculation ensures that the gas phase and condensed $\mathrm{HNO}_{3}$ and $\mathrm{H}_{2} \mathrm{O}$ are equal to the initial total $\mathrm{HNO}_{3}$ and $\mathrm{H}_{2} \mathrm{O}$. The model then derives the condensed aerosol mass concentration (or aerosol volume concentration). Finally, the refractive index is calculated from the equilibrium composition [Luo et al., 1996].

\subsection{Mie Calculations}

[20] The particle backscatter coefficient $\beta_{\text {Par }}$ can then be simulated using Mie theory, the simulated size distribution and refractive index according to equation (1). The molecular or Rayleigh backscatter coefficient, $\beta_{\text {Ray }}$, is calculated from the RRT temperature and pressure. 


\subsection{Determination of the Size Distribution Parameters}

[21] The size distribution parameters are derived from comparison between simulated and measured backscatter coefficients. The model is used to calculate the three backscatter coefficients $\left(\beta_{355 \mathrm{~nm}}, \beta_{532 \mathrm{~nm}}\right.$ and $\left.\beta_{1064 \mathrm{~nm}}\right)$ and associated color ratios $\left(\mathrm{CR}_{355 \mathrm{~nm}}\right.$ and $\left.\mathrm{CR}_{1064 \mathrm{~nm}}\right)$ as a function of size distribution parameters for the environmental conditions of each lidar observation. A look-up table is generated accordingly. We then select from the table all the simulated cases that fit the lidar measurements ( $\beta$ and CR) within the corresponding measurements error bars. Note that the lidar ratios could also have been used as additional control variables in the size distribution algorithm [ $\mathrm{Del}$ Guasta et al., 1994].

[22] Taking lidar backscatter uncertainties into account, the search for possible matches leads to formation of a three-dimensional solution cluster of points $\left(\mathrm{N}_{\mathrm{o}}, \mathrm{r}_{\mathrm{m}}, \sigma\right)$. Preliminary analysis of the solution cloud shows that the best match cannot always be considered as solution because, in some rare cases, the best match solution corresponds to an unrealistic outlier. We are instead looking for a probable solution given the lidar uncertainties. The most probable solutions are expected to be in the densest part of the solution cluster, within $\pm 1 \sigma$ from the median values, with $\sigma$ being the standard deviation of the cluster. Therefore, solutions outside the $\pm 1 \sigma$ boundaries are discarded. This cluster-based filtering guarantees that unrealistic solutions are not accounted for in our analysis. The standard deviation $\sigma$ of the cluster is taken as a first-order estimate of the errors on the size distribution parameters. Then, the best match approach is used to find the solution which is selected among the filtered $\left(\mathrm{N}_{\mathrm{o}}, \mathrm{r}_{\mathrm{m}}, \sigma\right)$ cluster through least squares minimization of a cost function of the misfit between observations and model simulations. The control variables are the parameters of the PSC size distribution.

[23] In presence of volcanic aerosols or PSC, the size distribution of stratospheric particles is often bimodal [Deshler et al., 2003b]. Nonetheless, sensitivity tests have shown that our algorithm accurately retrieved the optically dominant mode (i.e., the mode corresponding to the highest lidar received signal). At the three commonly used wavelengths, the lidar appears to be sensitive to the higher-order moments of the size distribution [World Meteorological Organization, 2006]. Since small particles usually contribute little to the higher-order moments of the size distribution, they are difficult to characterize when their number density $\mathrm{N}_{\mathrm{o}}$ is low. However, when their concentration is high enough to be detected with the lidar, some accurate characterization can be performed. For instance, the ALOMAR RMR lidar has been used to characterize noctilucent cloud particles sizing around $50 \mathrm{~nm}$ from multicolor lidar backscatter measurements, with $\mathrm{N}_{\mathrm{o}}$ being around $120 \mathrm{~cm}^{-3}$ [Baumgarten et al., 2007].

[24] The size distribution retrieval methodology has been described in details and validated against independent balloon-borne size-resolved PSC measurements by Jumelet et al. [2008]. Here we are only presenting the salient and relevant features of the validation. Sensitivity tests were carried out to assess the impact of the assumption regarding unimodality. In the nondepolarizing region of the cloud probed by the balloon-borne OPC instrument, both the unimodal and dominant mode of the bimodal size distribution were retrieved in a satisfactory manner when compared to the reference size-resolved measurements [Deshler et al., 2000; Jumelet et al., 2008]. The total number density $\left(\mathrm{N}_{\mathrm{o}}\right)$ carries most of the uncertainties with errors reaching almost $50 \%$. The median radius and standard deviation were both retrieved within 5\% error of the reference values. The total retrieval errors (derived from the cluster spreads) for the median radius and standard deviation were estimated to be lower than $10 \%$. The retrieved particle surface area density and volume (A) and (V) of unimodal distributions were found within $60 \%$ and $40 \%$ respectively of the reference balloon-borne values. The estimated retrieval errors on $\mathrm{A}$ and $\mathrm{V}$ derived directly from the estimated errors on $\mathrm{N}_{\mathrm{o}}, \mathrm{r}_{\mathrm{m}}$ and $\sigma$ are found to be around $30 \%$.

[25] Deshler et al. [2000] also performed a determination of the refractive index through comparisons between aerosol scattering and balloon-borne size-resolved concentration measurements. This was used to check our refractive index calculation of refractive index. The composition model gives a refractive index of 1.45 at $355 \mathrm{~nm}$ and down to 1.43 at $1064 \mathrm{~nm}$ whereas Deshler et al. [2000] derived an average value of 1.47 over a similar wavelength interval. When using this refractive index instead of the one calculated with by the model, the quality of the retrieval regarding particle surface and volume concentrations is substantially improved compared to the reference balloonborne reference measurements. This sensitivity test has a validation purpose and shows full consistency between the two analyses. It also highlights the strong sensitivity of the backscatter coefficient to the refractive index in our retrieval procedure. It is clear that the small bias in the refractive index results in additional errors that are not taken into account in our procedure because the composition model is assumed to be perfect. This should be kept in mind when analyzing the results.

[26] For the PSC event considered in the present paper, the ranges of parameters covered in the look-up table of simulated optical quantities are: $0.01 \mu \mathrm{m}<\mathrm{r}_{\mathrm{m}}<5 \mu \mathrm{m}$, $1.01<\sigma<3$, and $10^{-4}<\mathrm{N}_{\mathrm{o}}<10 \mathrm{~cm}^{-3}$. The temperatures are taken from the RRT retrieval (60-min-averaged lidar data). Nitric acid and water vapor are initialized with zonally averaged MLS data. At the PSC altitude, MLS data indicate on the first days of December a mixing ratio of nitric acid and water vapor of around 15 ppbv and 5 ppmv, respectively, over northern Scandinavia. It is important to initialize the model with values of nitric acid and water vapor as accurate as possible. Indeed, a sensitivity test is performed by retrieving the PSC size distribution over the same 2-h lidar period (1600-1800 UTC) with the MLS initialization and with the commonly used initialization of 10 ppbv $\mathrm{HNO}_{3}$ and 5 ppmv $\mathrm{H}_{2} \mathrm{O}$ mixing ratios. Differences of $20 \%$ on $\mathrm{N}_{\mathrm{o}}, 6 \%$ on $\mathrm{r}_{\mathrm{m}}$ and $2 \%$ on $\sigma$ were found. Nonetheless, error bars on the retrieved parameters are still overlapping.

[27] In refractive index calculations, PSC are assumed to be optically nonabsorbing. Lidar errors are estimated to be between $10 \%$ and $20 \%$, depending on the integration time and on the wavelength considered, the $1064 \mathrm{~nm}$ channel carrying the largest uncertainties owing to the Klett inversion 


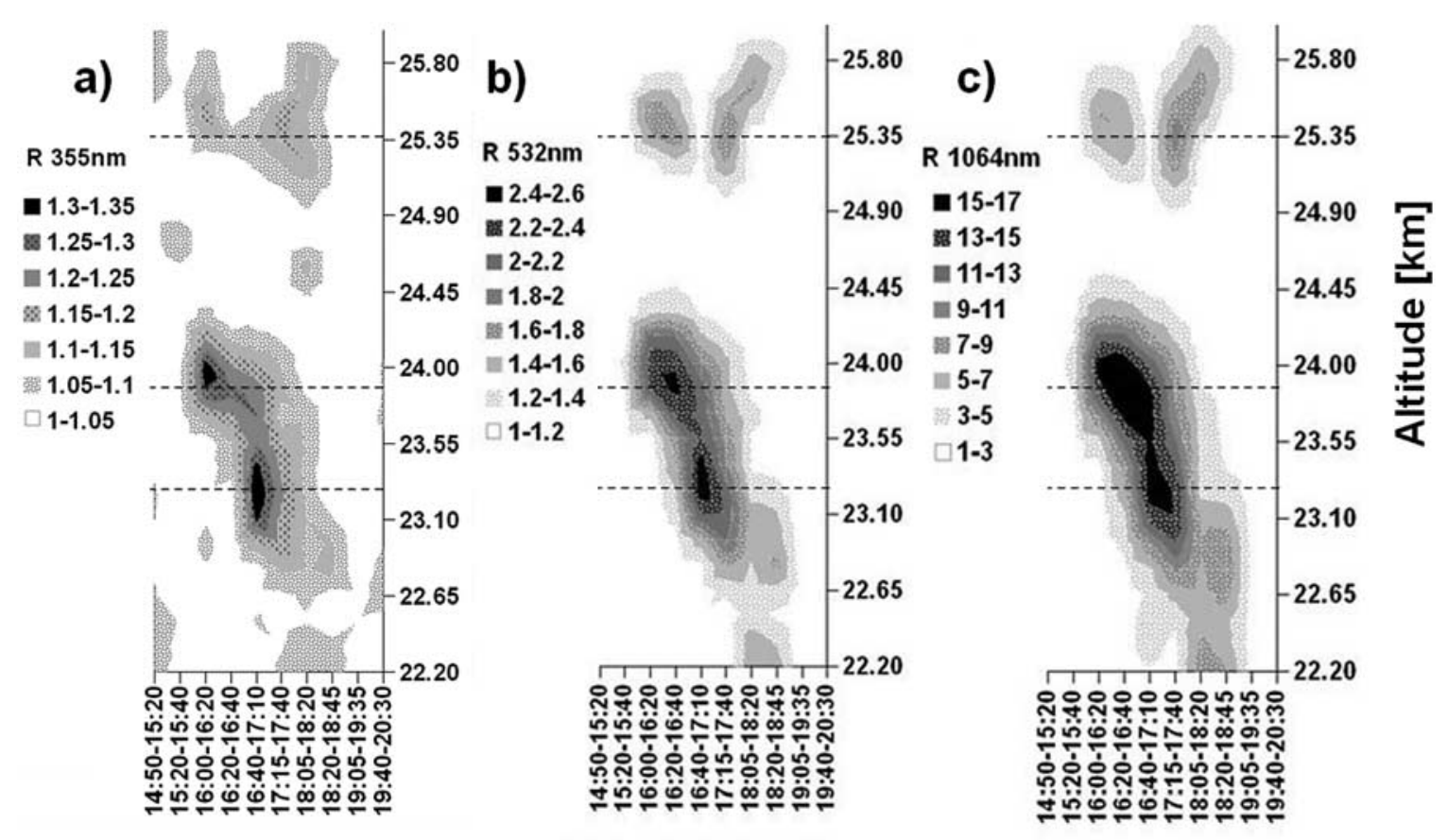

Time intervals

Figure 1. Time series of the backscatter ratio between 1500 and 2000 UTC at (a) 355, (b) 532, and (c) $1064 \mathrm{~nm}$ on 6 December 2005. The time axis is not linear. The time intervals are variable because they are chosen to match the PSC structure, as defined by the backscatter ratios. The retrieval altitudes matching the three main layers are marked with dotted lines. Note that the 1845-1905 UTC interval is missing because the signal-to-noise ratio was not sufficiently good for the lidar data to be properly inversed.

and the errors resulting from the use of the lidar ratio at $532 \mathrm{~nm}$ for the lidar inversion at $1064 \mathrm{~nm}$.

\section{Results and Discussion}

\subsection{PSC Event}

\subsubsection{Optical Properties Derived by Lidar}

[28] An overall view of the PSC event is featured in Figure 1, showing the time series of the backscatter ratio profiles at 355, 532 and $1064 \mathrm{~nm}$. The labels on the $x$ axis refer to the 10 lidar-integration time intervals. The PSC was detected between around 1500 and 2000 UTC in the 22- to $27-\mathrm{km}$ altitude range. The layered structure and high temporal variability clearly appear. The PSC roughly extends from 22 to $26 \mathrm{~km}$ in two main layers centered around 24 and $25.5 \mathrm{~km}$. The lower layer can be split into two sublayers. The size distributions are retrieved in two different ways. The retrieval is performed first at the altitude of the backscatter peak in each time interval, meaning that the retrieval altitude varies between around 23 and $24 \mathrm{~km}$ (see Figure 1). The size distribution is also retrieved at three fixed altitudes $(23.25 \mathrm{~km}, 23.85 \mathrm{~km}$ and $25.35 \mathrm{~km})$, chosen to fit the three layers appearing in the lidar backscatter time series of Figure 1. Highly enhanced backscatter ratios are observed from 1600 to 1900 UTC. We decompose this event into three parts: prior to $1600,1600-1900$, and after 1900 UTC. In order to follow the particle backscatter with an acceptable signal-to-noise ratio, while maintaining a sufficient time resolution in the analysis, the lidar data time series are decomposed into 10 intervals of 20 to $40 \mathrm{~min}$. The backscatter inversion and the size distribution retrieval are carried out with lidar data averaged over these intervals. These results are used to decompose and study the PSC event. For validating the retrieval at these short integration time intervals, lidar data are also integrated over a 2-h time interval during the strong PSC period, between 1600 and 1800 UTC. This averaged data set does not provide information on the PSC temporal variability, but the associated particle size distribution can be compared against the results obtained with the short time intervals. The purpose is to check that the relatively short integration time does not affect adversely the quality and stability of the size distribution retrievals.

[29] Figure 2 shows the vertical profiles of the color ratios $\mathrm{CR}_{355 \mathrm{~nm}}$ and $\mathrm{CR}_{1064 \mathrm{~nm}}$ for a lidar integration time of $2 \mathrm{~h}$ (1600-1800 UTC time interval). Values of both color ratios appear to be unusual as compared to typical values for liquid PSC measurements. At the retrieval altitude (around $23.5 \mathrm{~km}), \mathrm{CR}_{355 \mathrm{~nm}}$ and $\mathrm{CR}_{1064 \mathrm{~nm}}$ are around 1.2 and 0.9 , respectively. In contrast, for typical nondepolarizing (i.e., liquid) PSC, $\mathrm{CR}_{355 \mathrm{~nm}}$ and $\mathrm{CR}_{1064 \mathrm{~nm}}$ are found around 2 and 0.3 , respectively [Deshler et al., 2000; Blum et al., 2006]. In these two studies, $r_{m}$ was found to be around $0.3 \mu \mathrm{m}$ which is more typical of LTA PSC. In our case, the small $\mathrm{CR}_{355 \mathrm{~nm}}$ and large $\mathrm{CR}_{1064 \mathrm{~nm}}$ suggest the presence of large particles, probably NAT particles. In the third part of the PSC event, after $1900 \mathrm{UTC}, \mathrm{CR}_{355 \mathrm{~nm}}$ increases to values around 2-2.5 whereas $\mathrm{CR}_{1064 \mathrm{~nm}}$ decreases slightly. Therefore, very different particle size distributions are expected to be retrieved within the measurement period considered. 

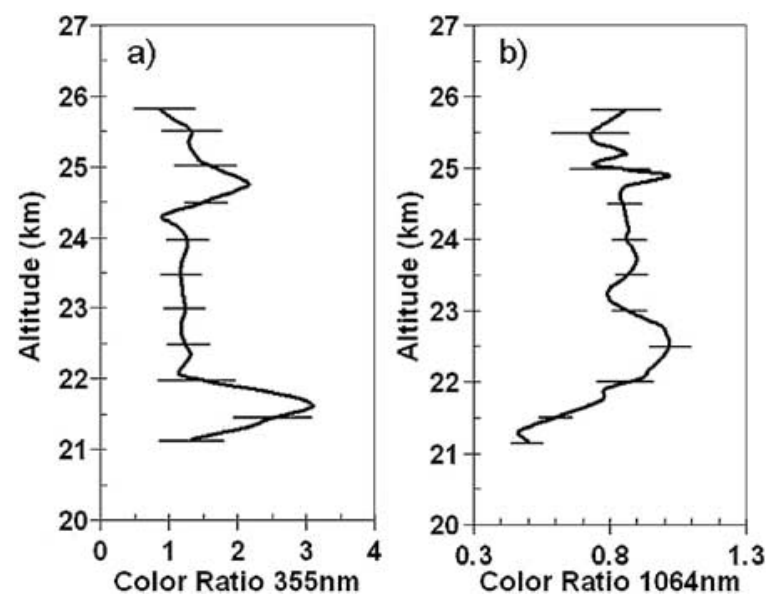

Figure 2. Vertical profiles of (a) $R_{355 \mathrm{~nm}}$ and (b) $\mathrm{CR}_{1064 \mathrm{~nm}}$ for the 1600-1800 UTC time interval.

\subsubsection{Temperature Derived by Lidar}

[30] A PTU sonde was launched at 1540 UTC at the Andøya Rocket Range and reached the altitude of the cloud at about 1630 UTC. This temperature measurement is used in the calibration of the RRT following the approach described in section 2.3. The 30-min and 60-min timeresolved RRT temperatures are shown in Figures $3 \mathrm{a}$ and $3 \mathrm{~b}$, respectively. The 60-min temperatures are consistent with temperatures provided by ECMWF, with an average temperature of $190 \mathrm{~K}$ throughout the PSC altitude range. The 30-min time series obviously carry larger errors owing to the shorter lidar integration time. The difference between the 30-min RRT temperatures and PTU temperatures is plotted versus altitude in Figure $3 \mathrm{c}$. The difference is found to be around $+2 \mathrm{~K}$ at the three previously identified PSC layers.

[31] Figure 3a reveals strong gravity wave activity. The 60 -min time series also indicate wave patterns but it is less

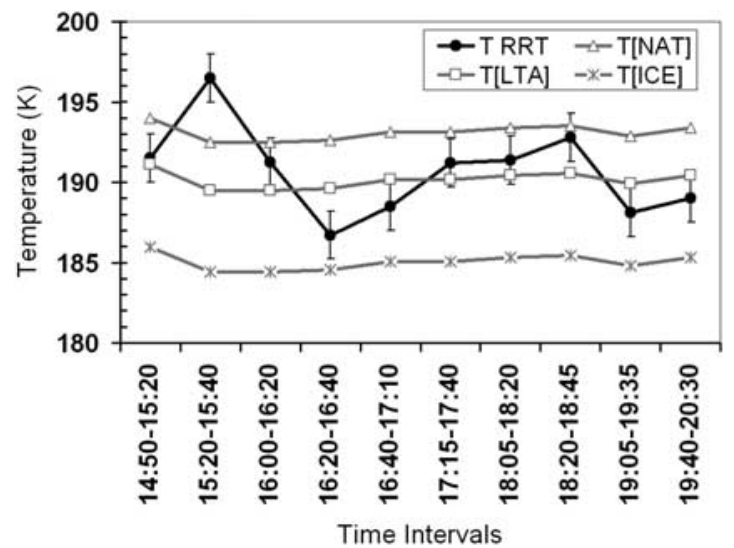

Figure 4. RRT temperature and temperature thresholds for LTA, NAT, and ICE particles in the 10 time intervals.

noticeable (see Figure 3b). A simple visual inspection of the plots indicates that the wave time period is about $1 \mathrm{~h}$ with an associated vertical period of about $2 \mathrm{~km}$. The 30-min time resolved RRT temperature displays a wave amplitude of around $10 \mathrm{~K}$. It is worth noting that strong backscatter is found to be correlated with local temperature minima, indicating that the structures in the RRT temperature time series are certainly real features and not retrieval artifacts (see Figures 1 and 3). Meilinger et al. [1995] stated that rapid temperature fluctuations may lead to droplets whose stoichiometry is close to that of NAT particles and freezing experiments showed that it is a pathway for NAT PSC formation. If gravity wave activity were present a few hours prior to the measurements, the presence of solid particles could be expected. Synoptic temperatures from ECMWF were below $\mathrm{T}_{\mathrm{NAT}}$ and around $\mathrm{T}_{\mathrm{LTA}}$ in the last $24 \mathrm{~h}$ (see section 4.1.3).

[32] Figure 4 shows the time series of the RRT temperature (derived over the 10 lidar integration time intervals) at

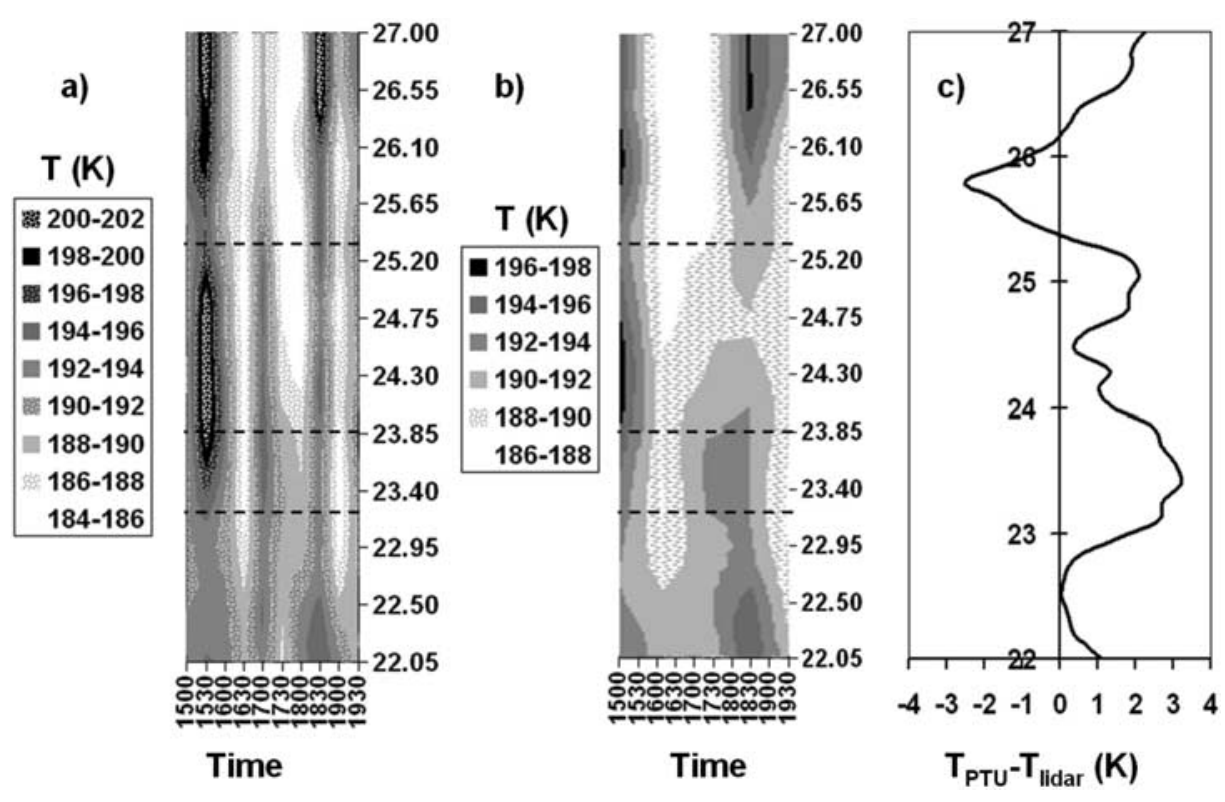

Figure 3. Time series of the RRT temperature between 1500 and 2000 UTC on 6 December 2005 integrated over (a) $30 \mathrm{~min}$ and (b) $60 \mathrm{~min}$. (c) Temperature difference between the 30-min RRT and the PTU temperature measurements. The PTU radiosonde reached the PSC altitude at around 1600 UTC. 


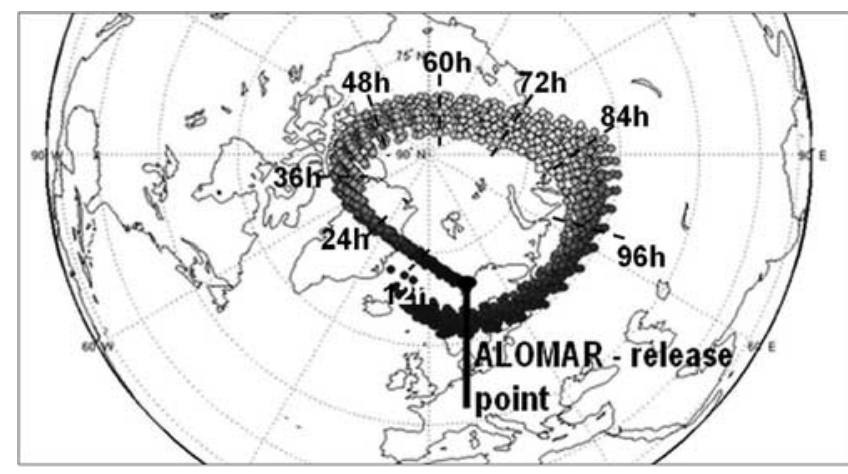

Figure 5. Air mass back-trajectories computed with the FLEXPART model. Particles have been released between 22.5 and $26.5 \mathrm{~km}$ above ALOMAR. The color bar indicates the time elapsed from the release point (lidar detection time), back to 5 days in time. The vortex is stable, and associated temperature history (nonplotted) indicates favorable PSC conditions back to $24 \mathrm{~h}$ before the measurements. A mark is placed every $12 \mathrm{~h}$ elapsed.

the altitude of the backscatter peak for each time interval (between 23 and $24 \mathrm{~km}$ ) along with the temperature thresholds of LTA, NAT and ice particles. $\mathrm{T}_{\text {LTA }}$ is identified as the temperature at which the $\mathrm{HNO}_{3}$ weight fraction exceeds $10 \%$ in the condensed phase [Luo et al., 1995]. In each time interval, $\mathrm{T}_{\text {LTA }}$ is calculated at every backscatter peak altitude assuming 15 ppbv $\mathrm{HNO}_{3}$ and 5 ppmv $\mathrm{H}_{2} \mathrm{O}$ as stated in section 3.3. As temperature remains the key factor controlling PSC microphysics, this PSC peak altitude is expected to match the coldest temperature. $\mathrm{T}_{\mathrm{NAT}}$ and $\mathrm{T}_{\mathrm{ICE}}$ are calculated from work by Hanson and Mauersberger [1988]. Very significant fluctuations in temperature are apparent on Figure 4. The temperature drops below $\mathrm{T}_{\mathrm{LTA}}$ around 1630 and after 1900 UTC. Taking into account the uncertainties on the RRT measurements, $\mathrm{T}$ could also be below $\mathrm{T}_{\text {LTA }}$ around 1500 UTC. One can also notice the correlation between the cooling around 16:30 and the highest backscatter ratios (see Figure 1 and Figure 8 in section 4.2.1). The overall evolution of the temperature with respect to PSC threshold temperatures indicates the presence of different particle types between 1500 and 2000 UTC. However, the errors on the temperature are still too large to conclude unambiguously on the existence domain of the different PSC particle types. Finally, even if the temperature was known accurately, it can only prove PSC existence when PSC are in thermodynamical equilibrium with the gas phase. The RRT temperatures have revealed the presence of gravity waves that may prevent particles from reaching equilibrium because of rapid temperature fluctuations. In addition, energy barriers may prevent the formation of the stable phase thermodynamically, for instance, NAT.

\subsubsection{Thermodynamical Context and PSC Classification}

[33] It is possible that the multilayered structure of the cloud and its temporal variability originate from temperature fluctuations [e.g., Deshler et al., 2003b] or from the sampling of completely distinct air masses that have different temperature histories and chemical compositions. The latter situation could occur when, for example, mixed air masses are sampled on the edge of the vortex. We use a high-resolution PV (potential vorticity) advection model forced by ECMWF analyses (resolution $0.5^{\circ}$ ) to identify the position and extent of the polar vortex at the PSC altitudes. On 6 December, the polar vortex is centered between $80^{\circ}$ and $90^{\circ} \mathrm{N}$ at the $500 \mathrm{~K}$ and $550 \mathrm{~K}$ surfaces with a large lobe spreading over Norway. The PSC layers appear to form on the edge of the vortex and little air mixing is observed during the 5 days prior to the lidar measurements (starting time of the back trajectories).

[34] The thermal history (and associated cooling rate C) remains a critical factor in PSC formation. We compute backtrajectory clusters using a Lagrangian advection-dispersion model [Stohl et al., 1998]. A large number of air mass parcels are released above ALOMAR at the PSC altitudes between 23 and $26 \mathrm{~km}$, and they are advected-dispersed backward in time from 1 December using ECMWF analyses. Back trajectories are presented in Figure 5. The dispersion of the back trajectories is limited because air mass parcels are released on the edge of a stable vortex within a well stratified flow. The PV value along each trajectory (not shown) generally shows little variations indicating that the transport remains essentially isentropic.

[35] Temperature history of the air cluster sampled by the lidar is plotted against time elapsed since lidar detection in Figure 6. The ECMWF meteorological analyses are used in this calculation. $\mathrm{T}_{\mathrm{LTA}}$ and $\mathrm{T}_{\mathrm{NAT}}$ are also plotted for the last $30 \mathrm{~h}$. Please recall that the RRT temperatures have to be treated with caution because of the uncertainties in the ECMWF analyses and the absence of small-scale temperature fluctuations. The synoptic temperatures decrease by about $12 \mathrm{~K}$ during the last 2 days before sampling. They remain below $\mathrm{T}_{\mathrm{NAT}}$ during the last $35 \mathrm{~h}$ prior to PSC detection. The cloud is likely to have been formed during 5 December. The RRT temperature vertical profiles suggest that small-scale temperature fluctuations of large amplitudes were superimposed onto the slow variations of the synoptic temperatures. The low backscatter ratios and the synoptic ECMWF temperatures well above the ice frost point (even when accounting for temperature variations caused by propagating gravity waves) make the presence of ice PSC very unlikely. Therefore, the PSC event is certainly composed of LTA and NAT, either in different layers, or in a mixed composition.

[36] During the last $24 \mathrm{~h}, \mathrm{~T}$ is within $1 \mathrm{~K}$ of $\mathrm{T}_{\mathrm{LTA}}$ and the presence of LTA PSC is possible by the time of the measurement session, even if other indices (color ratios and cooling rate discussed below) favor presence of NAT

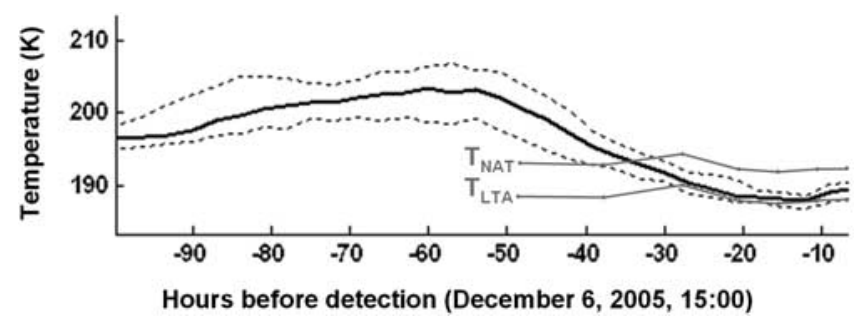

Figure 6. Temperature history of the air masses back to $90 \mathrm{~h}$ from lidar detection time on 6 December 20051500 UTC above the ALOMAR observatory. Dotted lines denote the minimum and maximum values within the air cluster along the back trajectory. 
particles. Overall, the synoptic temperatures and their temporal evolution within the sampled air masses (see Figure 6) unambiguously confirm that thermodynamical conditions were met for the formation of significant nitric acid PSC.

[37] PSC can be distinguished on the basis of backscatter, color ratios, and cooling rate $(\mathrm{C})$ values. Fierli and Hauchecorne [2001] concluded from 2 years of PSC observations at ALOMAR that NAT PSC are also often formed from air masses cooling below $\mathrm{T}_{\mathrm{NAT}}$ during the last $24 \mathrm{~h}$ before PSC detection. In our case, the cooling rate, $\mathrm{C}$, averaged over all the back trajectories is found to be around $6 \mathrm{~K} / \mathrm{d}$ in the last $24 \mathrm{~h}$. One has to recall that the small-scale wave structures seen in the RRT temperature are not reproduced in the meteorological analyses that we use to force the Lagrangian model. Large fluctuations in $\mathrm{C}$ around this $6 \mathrm{~K}$ per day average value are expected during the PSC period. Past classifications indicate that, for C less than $5 \mathrm{~K}$ a day, the formation of NAT particles tends to be favored [Beyerle et al., 1994]. The cooling rate provides just an indication about the potential for PSC formation, the temperature needs to drop and stay within a specific range (see Figure 6). It is likely that the length of time an air parcel spends below $\mathrm{T}_{\mathrm{NAT}}$ is important for NAT formation because of the energy barrier to NAT nucleation. There are also classifications of LTA/NAT based on the $532 \mathrm{~nm}$ backscatter and color ratios [Mehrtens et al., 1999]. According to them, and considering the 1600-1800 UTC time intervals associated to the highest backscatter ratios, NAT presence is favored in our case $\left(\mathrm{R}_{532 \mathrm{~nm}} \approx 2\right.$ and $\left.\mathrm{CR}_{1064 \mathrm{~nm}} \approx 0.8\right)$.

[38] A second lidar located at ALOMAR measured the $532 \mathrm{~nm}$ cross-polarized signal during the RMR lidar session. Preliminary data analysis indicates some depolarization during the 1600-1800 UTC period suggesting the presence of solid particles. A maximum depolarization ratio of 5\% was estimated at 1700 UTC. The depolarization ratio is negligible before 1600 and after 1900 UTC. Note that this depolarization measurement is not entirely reliable owing to a possible cross talk (i.e., incomplete separation of the parallel and perpendicular channels during data acquisition) in the lidar instrument (M. Frioud, personal communication, 2005). Since cross talk reduces the depolarization ratio, this strengthens the hypothesis of NAT presence. On the basis of the backscatter ratio versus depolarization classification [David et al., 2005], our 1600-1800 UTC lidar data lie between the two former type I PSC classes (NAT and/or LTA). It is worth keeping in mind that determining the physical phase of a PSC is not trivial using only backscatter ratio and depolarization measurements. Solid particles in low number densities cannot always be clearly detected on the perpendicular backscatter signal [Biele et al., 2001].

[39] From the information gathered, we are not able to determine with confidence the exact PSC type (NAT and/or LTA). Despite borderline values, most classifications tend to favor the presence of solid particles for our cloud, but the low depolarization suggests predominance of liquid particles. The RRT temperature is not accurate enough to discriminate unambiguously between LTA/NAT for the most part of the PSC event, even if LTA PSC are certainly dominant before 1600 and after 1900 UTC. An analysis at high resolution is needed to identify the structure of this PSC event. We will apply our size distribution retrieval to the time-resolved data set even if particles may not necessarily be spherical during some of the time intervals.

\subsection{Size Distribution Parameters}

[40] The size distribution retrieval algorithm described in section 3 is applied to 10 time intervals. To support the discussion on the PSC structure and presence of different particle types (LTA/NAT), the size distribution is first retrieved at the backscatter peak altitude of each time interval. This backscatter peak altitude has the optimum signal-to-noise ratio and therefore carries the lowest uncertainties. In a second time, the results will be presented at three fixed altitudes: $23.25,23.85$ and $25.35 \mathrm{~km}$. These altitudes fit the PSC backscatter behavior appearing in Figure 1. The associated results help in characterizing the vertical structure of the PSC cloud. Note that, even if the size distributions are retrieved at fixed altitudes, the sequence of results cannot been viewed as a description of the temporal evolution of a single PSC within an air mass (i.e., a so-called Lagrangian study). Because of the air motion (see Figure 5), the lidar does not probe the same air mass during the measurement session. Therefore, when analyzing the results, one has to keep in mind that the time series presented thereafter refer to different air masses and hence, the present analysis is not a Lagrangian study.

\subsubsection{PSC Classification From Size Distribution Parameters}

[41] Figure 7a shows the time series of the retrieved size distribution parameters, $\mathrm{N}_{\mathrm{o}}, \mathrm{r}_{\mathrm{m}}$ and $\sigma$, at the backscatter peak of each time interval. The time series are consistent with those of the lidar backscatter (see Figure 1) in that here again, we can decompose the event into three parts: before 1600, 1600-1900, and after 1900 UTC. Backscatter ratios at 355, 532 and $1064 \mathrm{~nm}$ along with RRT temperature have been gathered in Figure 7b. Each side of the 1600-1900 UTC time interval displays on Figure $7 \mathrm{a}$ a similar size distribution $\left(\mathrm{N}_{\mathrm{o}} \in[1 ; 10] \mathrm{cm}^{-3}, \mathrm{r}_{\mathrm{m}} \approx 0.15 \mu \mathrm{m}, \sigma \approx 1.2\right)$. These values are close to typical LTA values [Deshler et al., 2000; Blum et al., 2006]. The ranges of backscatter coefficient and color ratio values are also rather indicative of LTA. Overall, there is little doubt about the nature of PSC before 1600 and after 1900 UTC, this being confirmed by a negligible depolarization ratio during these two periods. For the strong backscatter period, between 1600 and 1800 UTC, the retrieved size distribution parameters and associated errors in percentage are: $\mathrm{N}_{\mathrm{o}}=0.04 \mathrm{~cm}^{-3}(30 \%), \mathrm{r}_{\mathrm{m}}=1.50 \mu \mathrm{m}$ $(15 \%)$ and $\sigma=1.37(10 \%)$. As expected from the color ratios, we retrieve very large particle radii that are sometimes observed in the stratosphere for liquid particles but tend to be more typical of solid NAT particles. Deshler et al. [2000, 2003b] reported balloon-borne OPC measurements of bimodal Arctic PSC. For instance, in the nondepolarizing regions, lognormal parameters of the large particle mode were found to be equal to: $\mathrm{N}_{\mathrm{o}}=5.10^{-3} \mathrm{~cm}^{-3}, \mathrm{r}_{\mathrm{m}}=1.74 \mu \mathrm{m}$ and $\sigma=1.33$ over ALOMAR [Deshler et al., 2000]. This mode was the secondary and nondominant mode because of very low particle concentration $\left(0.005 \mathrm{~cm}^{-3}\right)$. Lidar measurements were also performed at ALOMAR simultaneously to the OPC measurements. When applied to this lidar data set, our size distribution algorithm retrieved successfully the small particle mode $\left(r_{\mathrm{m}}=0.40 \mu \mathrm{m}\right)$ which is optically dominant. This mode was associated to a total particle 


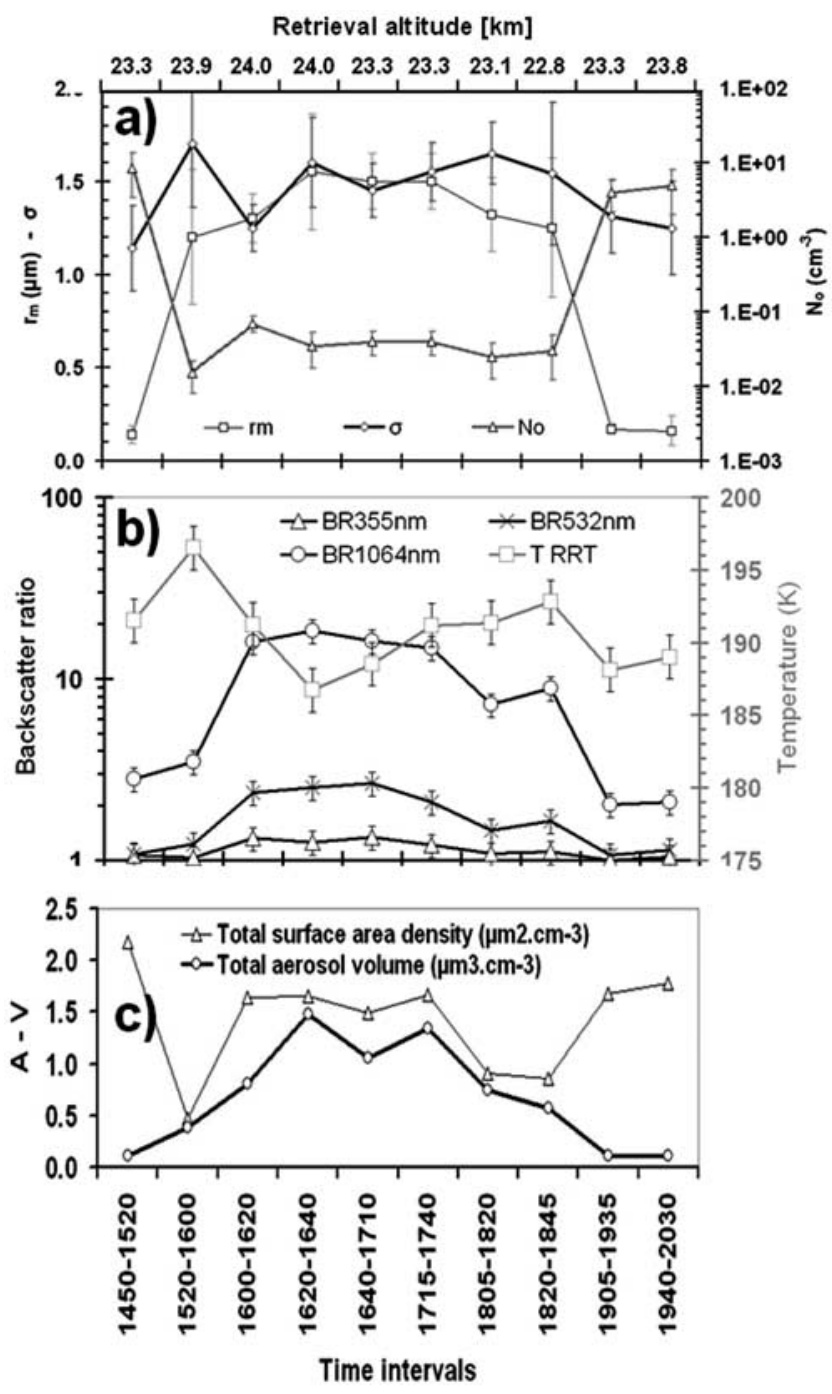

Figure 7. (a) Time series of the size distribution parameters retrieved from multiwavelength lidar measurements performed at ALOMAR on 6 December 2005 at the backscatter peak altitude of each time interval. Retrieved parameters on the 1600-1800 UTC time interval (nonplotted) are $\mathrm{N}_{\mathrm{o}}=0.040 \mathrm{~cm}^{-3}(19 \%), \mathrm{r}_{\mathrm{m}}=1.50 \mu \mathrm{m}(15 \%)$, and $\sigma=1.37$ (10\%). (b) Backscatter ratios at 355, 532, and $1064 \mathrm{~nm}$ associated with RRT temperature plotted on the right $y$ axis. (c) Time series of the total particle surface area density (A) and volume $(\mathrm{V})$.

volume of $1.92 \mu \mathrm{m}^{3} \mathrm{~cm}^{-3}$ whereas the particle volume of the large mode was only $0.16 \mu \mathrm{m}^{3} \mathrm{~cm}^{-3}$.

[42] The total surface area density (A) and volume (V) associated to parameters of Figure 7a can be calculated as follows:

$$
A=N_{\mathrm{o}} \cdot 4 \pi \mathrm{r}_{\mathrm{m}}^{2} \cdot e^{\left[2 \cdot \ln ^{2} \sigma\right]} \text { and } V=N_{\mathrm{o}} \cdot \frac{4 \pi}{3} \mathrm{r}_{\mathrm{m}}^{3} \cdot e^{\left[\frac{[}{2} \ln ^{2} \sigma\right]} .
$$

[43] $\mathrm{A}$ and $\mathrm{V}$ are plotted in Figure 7c. As expected, the total volume peaks within the 1600-1900 UTC period. This is consistent with the lowest temperatures and the largest backscatter ratios observed during this period. It is also worth noting that the effect of the slight warming around 1700 UTC (better seen on the 30-min RRT temperature in Figure 3a) is noticeable in Figure $7 \mathrm{~b}$ as well as in Figure 7c through a local decrease in the total particle volume. The rather odd feature is the variation of the aerosol surface area A during the entire measurement period. $\mathrm{A}_{1600-1900}$ (during the 1600-1900 UTC period) is of the same order as before 1600 and after 1900 UTC whereas $\mathrm{V}_{1600-1900}$ is an order of magnitude larger than V before 1600 and after 1900 UTC. How is it possible for the surface area to remain more or less unchanged when the condensed volume increases by an order of magnitude? From microphysical considerations, one would expect $\mathrm{A}$ and $\mathrm{V}$ to be correlated. When $\mathrm{HNO}_{3}$ and $\mathrm{H}_{2} \mathrm{O}$ condense/evaporate onto/from particles, particles grow/shrink. As a result, $\mathrm{A}$ and $\mathrm{V}$ are expected to increase/ decrease together and hence are expected to follow the same behavior. The local $\mathrm{H}_{2} \mathrm{O}$ and $\mathrm{HNO}_{3}$ content, and the size distributions of the preexisting sulfuric acid aerosol particles on which the PSC were formed should be similar for all the PSC observed during the entire measurement period. The breakdown in the expected correlation between $\mathrm{A}$ and $\mathrm{V}$ mainly originates from the change in $\mathrm{N}_{\mathrm{o}}$ by about 2 orders of magnitude (see Figure 7a). One of the key assumptions in our retrieval algorithm is the unimodality of the particle size distribution. In reality, PSC distributions can be bimodal. The second mode often has a very low particle number density, for instance, when NAT PSC are present (typically from $10^{-3}$ to $10^{-1} \mathrm{~cm}^{-3}$ [Fahey et al., 2001; Tsias et al., 1999]) compared to the preexisting sulfuric acid aerosol particles (typically around $10 \mathrm{~cm}^{-3}$ ). Two modes could coexist in the PSC cloud observed between 1600 and 1900 UTC. If the large particle mode dominates the lidar optical signal, the retrieved size distribution parameters are likely to correspond to this mode. Consequently, the surface area derived for this time interval would mostly account for the large particle mode. The total surface area would likely be underestimated because the surface area of the small particle mode would largely be missing. This point requires some quantitative sensitivity model analysis.

[44] A model test is performed to see what parameters are retrieved in those conditions. We assume that the small particle mode is similar to the mode retrieved before 1600 and after 1900 UTC $\left(\mathrm{N}_{\mathrm{o}}=5 \mathrm{~cm}^{-3}, \mathrm{r}_{\mathrm{m}}=0.16 \mu \mathrm{m}\right.$ and $\left.\sigma=1.25\right)$ and that the large particle mode is similar to the mode retrieved between 1600 and 1900 UTC $\left(\mathrm{N}_{\mathrm{o}}=0.04 \mathrm{~cm}^{-3}\right.$, $\mathrm{r}_{\mathrm{m}}=1.50 \mu \mathrm{m}$ and $\sigma=1.35$ ). We use the direct model to calculate the optical quantities corresponding to this bimodal distribution. Finally, these modeled lidar values are injected into the size distribution retrieval algorithm assuming lidar errors ranging from 10 to $25 \%$. The results are presented in Figure 8. The retrieved parameters $\left(\mathrm{N}_{\mathrm{o}}=0.02 \mathrm{~cm}^{-3}, \mathrm{r}_{\mathrm{m}}=\right.$ $1.43 \mu \mathrm{m}$ and $\sigma=1.50$ ) correspond to an unimodal "optically equivalent" size distribution. The retrieved values are very close to the parameters of the large particle mode. The backscatter signal produced by the large particle mode is 4 and 5 times larger than the signal produced by the small particle mode at 532 and $1064 \mathrm{~nm}$, respectively. Despite a similar surface area for both modes (around $1.5 \mu \mathrm{m}^{2} \mathrm{~cm}^{-3}$ ), the small particle mode is largely hidden by the large particle mode that contains most of the aerosol volume $\left(V_{2}=\right.$ $0.85 \mu \mathrm{m}^{3} \mathrm{~cm}^{-3}$ compared to $V_{1}=0.11 \mu \mathrm{m}^{3} \mathrm{~cm}^{-3}$ in Figure 8). This result confirms that our size distribution retrieval 


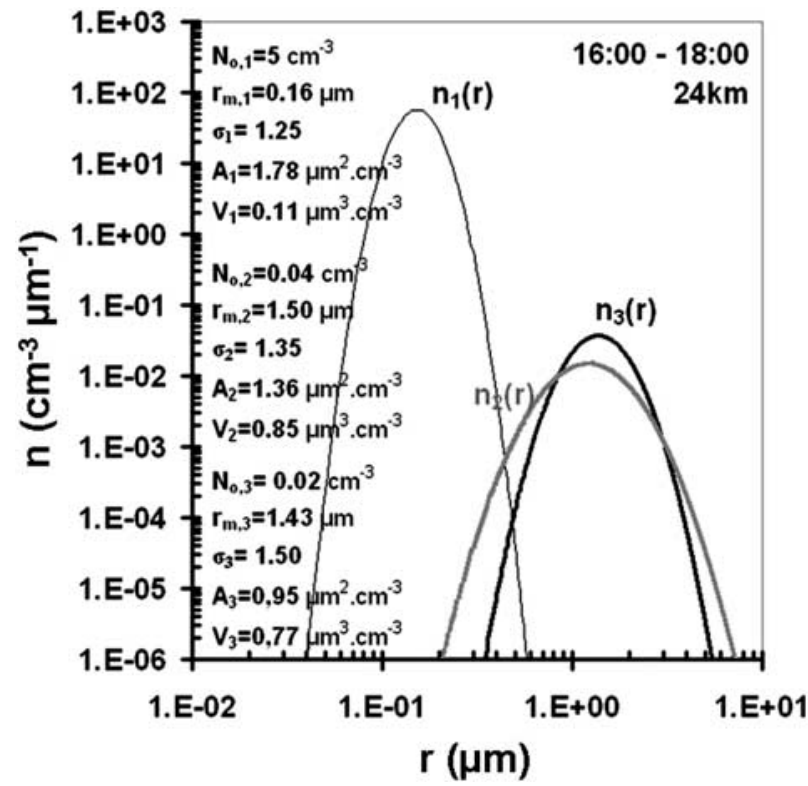

Figure 8. The two modes $\left(\mathrm{n}_{1}\right.$ and $\left.\mathrm{n}_{2}\right)$ of the particle size distribution retrieved during the lidar session. The $n_{3}$ size distribution is retrieved using a bimodal look-up table including the small mode $\mathrm{n}_{1}$. The dominant mode featuring larger particle volume is retrieved. The wavelengths used in the retrieval procedure are 355, 532, and $1064 \mathrm{~nm}$.

algorithm is most sensitive to the higher-order moments of the size distribution, for both the considered spectral window (355 nm to $1064 \mathrm{~nm}$ ) and the typical particle size (below and around $1 \mu \mathrm{m}$ ) [World Meteorological Organization, 2006; Jumelet et al., 2008].

\subsubsection{Vertical Structure}

[45] Figures 9a, 9b and 9c show the size distribution parameter time series retrieved at $23.25,23.85$ and $25.35 \mathrm{~km}$ respectively. At 23.25 and $25.35 \mathrm{~km}$, some time intervals (at the beginning or end of the measurement period) have a poor signal-to-noise ratio making the inversion (lidar + retrieval) very difficult to succeed. The retrieved size distributions are not reliable nonetheless particle sizes are estimated below $0.1 \mu \mathrm{m}$ on these time intervals, indicating presence of small LTA particles or binary aerosols. These time intervals are encased in boxes in Figures 9a and 9c. In presence of particles having a median radius lower than $0.1 \mu \mathrm{m}$, the $\mathrm{N}_{\mathrm{o}}$ and $\sigma$ parameters are set up to typical reference values $\left(\mathrm{N}_{\mathrm{o}}=10 \mathrm{~cm}^{-3}\right.$ and $\left.\sigma=1.7\right)$.

[46] The time series of the retrieved size distributions (Figure 9) at fixed altitudes display the PSC layers previously described. The two modes and their size distribution parameters can also be identified in Figure 9. Although the different modes are not found in exactly the same time intervals at the three altitudes, the size distribution parameters for the two modes are very similar at the three different altitudes: $\sigma$ oscillates around 1.5 for both modes, and $\mathrm{N}_{\mathrm{o}}$ is around $10 \mathrm{~cm}^{-3}$ for the small particle mode and between around 0.02 and $0.08 \mathrm{~cm}^{-3}$ for the large particle mode. The previous conclusions drawn out of the size distribution time series at the varying altitude of the backscatter peak (see Figure 7) are thus still valid for the results obtained at fixed altitudes. The same overall structure is observed: a mode of
LTA particles dominates the lidar signal at the beginning and end of the event, while a mode of larger particles, where NAT particles are highly probable, appears between around 1600 and 1900 UTC. Please note that while the three parts can still be identified during the PSC event, the time boundaries defining them now vary with altitude. For example, the NAT PSC period occurs slightly later at lower altitudes. At the highest altitude, the NAT period is shorter than in the middle part of the cloud (see Figure 9a). It is also interesting to note that the transition between the two PSC types is much sharper at the bottom and top altitudes (Figures 9a and 9c), whereas it appears smoother at the middle altitude.

[47] The higher PSC layer seems to be correlated with the RRT Temperature minima from Figure 3; The temperature is minimum around $1630 \mathrm{UTC}$, approaching $\mathrm{T}_{\mathrm{ICE}}$. The retrieved size distribution parameters do not correspond at all to ice particles. This is supported by the lack of very substantial depolarization. Owing to relatively low backscatter ratios and high temperatures, it remains highly improbable that ice particles are present.

[48] The retrieved size distributions are consistent with the lidar data displayed in Figure 1. The particle volume at each altitude (Figures 9d, 9e and 9f) peaks in the time interval when the backscatter ratio is the strongest and the temperature is at its minimum. This is expected but still represents an indirect validation of our retrieval algorithm. The breakdown of the correlation between $\mathrm{A}$ and $\mathrm{V}$, already noticed in Figure 7c, is still visible in plots of Figure 9 with the peaks being however slightly time shifted. This breakdown is more pronounced at $25.35 \mathrm{~km}$ (see Figure 9d). The values of $\mathrm{A}$ and $\mathrm{V}$ for the large mode (average $0.6 \mu \mathrm{m}^{2} \mathrm{~cm}^{-3}$ and $0.4 \mu \mathrm{m}^{3} \mathrm{~cm}^{-3}$, respectively) are both smaller than their values at the lower altitudes (average $1.5 \mu \mathrm{m}^{2} \mathrm{~cm}^{-3}$ and $1.0 \mu \mathrm{m}^{3} . \mathrm{cm}^{-3}$, respectively). It is consistent with the smaller backscatter ratios at higher altitudes, reflecting smaller particle surfaces and volumes. Note that the uncertainties on RRT temperatures prevent us from carrying out an analysis of the relationship between the local temperature and the PSC type at smaller scales.

\section{Summary and Concluding Remarks}

[49] The work presented here is a case study of the PSC event observed above the Arctic Lidar Observatory for Middle Atmosphere Research (ALOMAR), $\left(69^{\circ} \mathrm{N}\right)$, Norway, on 6 December 2005. Multiwavelength $(355,532$ and $1064 \mathrm{~nm})$ lidar measurements were performed with the ALOMAR RMR lidar. PSC were detected from around 1500 to 2000 UTC, with a main layer centered around $24 \mathrm{~km}$. Vibrational and rotational Raman measurements were also performed and the wavelength pairs $355 / 387 \mathrm{~nm}$ and $532 / 607 \mathrm{~nm}$ were used to derive the lidar backscatter coefficients. The lidar signal at 529 and $530 \mathrm{~nm}$ allowed for simultaneous temperature retrieval within the cloud using the RRT temperatures. These temperature profiles were used in the lidar inversion algorithm. Combining vibrational and rotational Raman detection increases the accuracy of the temperature and backscatter coefficient retrievals.

[50] The ECMWF temperature history as well as the retrieved RRT temperature profiles clearly indicate very favorable conditions for PSC formation. Strong gravity wave 

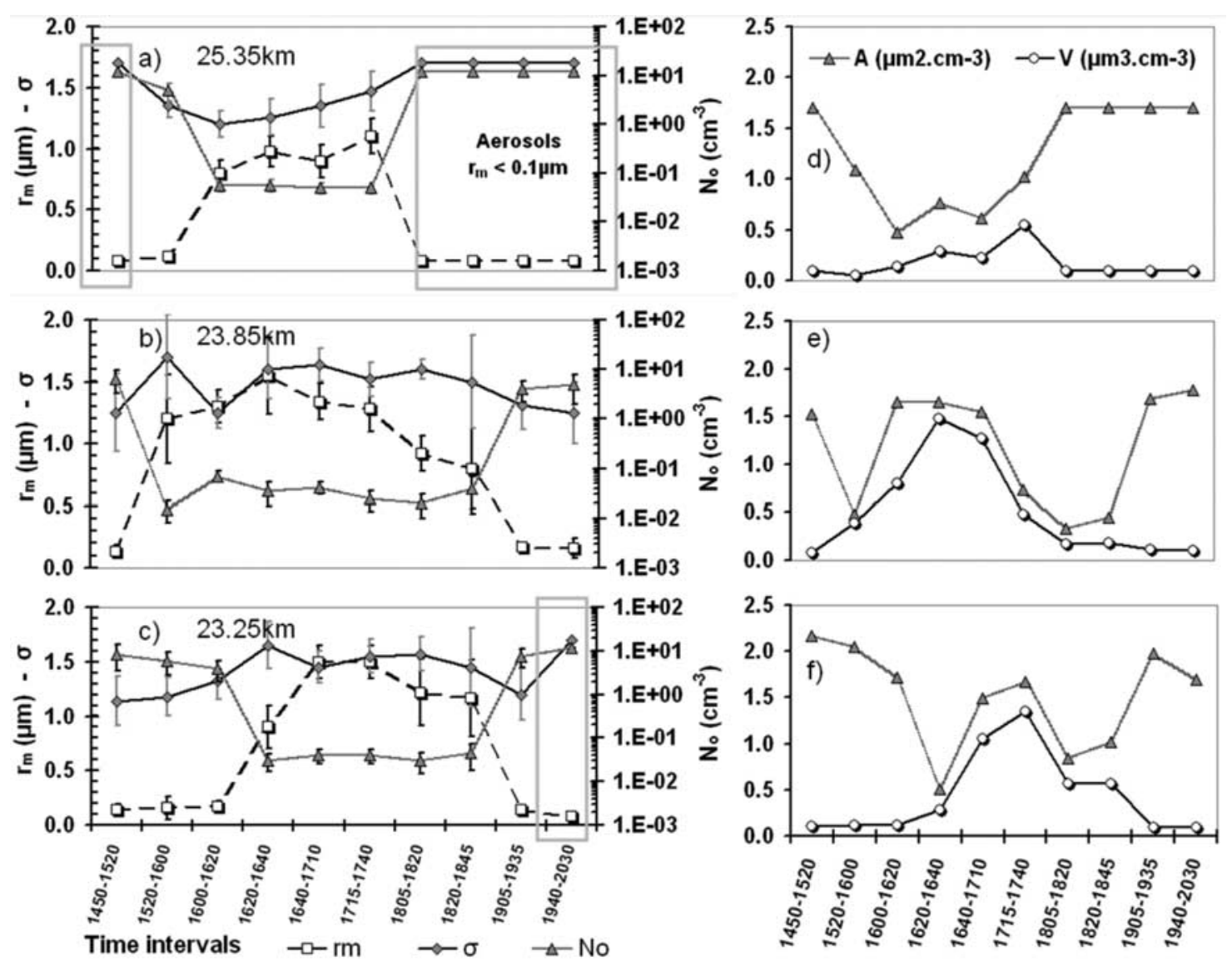

Figure 9. Time series of the size distribution parameters retrieved at (a) 23.25, (b) 23.85 , and (c) $25.35 \mathrm{~km}$ altitude and (d, e, and f) associated particle surface area density and volume.

activity is also very noticeable on the high-resolution RRT temperature time series. The lidar time series is decomposed into 10 time intervals from 1500 to 2000 UTC. The PSC size distributions are retrieved at the altitude of the backscatter peak and at three different fixed altitudes corresponding to the vertical structure of the PSC layers $(23.25,23.85$ and $25.35 \mathrm{~km}$ ), using a method combining measured and model-calculated multiwavelength backscatter coefficients and associated color ratios. The particles are assumed to be spherical and its size population is assumed to follow a unimodal lognormal size distribution. Lidar error measurements are taken into account in the retrieval process and the retrieved size distribution is selected through combination of statistical filtering and best match approaches.

[51] From the size distribution parameter and lidar backscatter time series, the event appears to be composed of three parts. For the time series of the backscatter peak altitude, the three parts are before $1600,1600-1900$, and after 1900 UTC. In each side of the 1600-1900 UTC time interval, the retrieved size distributions are similar with retrieved parameters indicative of LTA. It is further supported by a negligible measured level of depolarization. During the 1600-1900 UTC time period, much larger particles are retrieved with median radii of around $1.5 \mu \mathrm{m}$. The associated particle number density is low at around $0.04 \mathrm{~cm}^{-3}$. The temporal evolution of the particle number density suggests that the size distribution for the 1600-1900 UTC time period is bimodal. Model tests show that the algorithm successfully retrieves the size distribution of the optically dominant mode that is, in our case, the large particle mode. According to most classifications based on correlation plots of backscatter ratios and cooling rate, it is likely that the large particle mode is composed of solid NAT particles. It is also supported by depolarization ratio measurements peaking at 5\% around 17:00. There are caveats to the interpretation of the results during the 1600-1900 UTC period. Since the model uses Mie theory, the size distribution parameters are likely to be biased owing to the presence of solid particles. Therefore, our retrieved parameters should be viewed as rough estimates for this type of PSC. In general, spherical scatterers have a backscatter reduced by some ten percents with respect to the volume equivalent spheres [Reichardt et al., 2002]. It certainly requires more detailed optical calculations in order to estimate the impact of the spherical particle assumption on the size distribution retrieval. The condition regarding particle sphericity will be relaxed in the near future through implementation of T-Matrix calculations accounting for the aspherical particle aspect ratios in the model.

[52] Gravity wave activity may also cause the modeling of the particle composition assuming thermodynamical equilibrium with the gas phase to be erroneous. Nonetheless, even at short lidar integration times, the time series of the size distribution parameters derived from the lidar data appears to be reliable and somewhat consistent with the results obtained using other types of PSC characterization. 
[53] Finally, it is worth highlighting that this approach could be applied to study the variability of stratospheric aerosols from long-term data sets (i.e., the multiwavelength lidars of the NDACC network). We also plan in the near future to use this approach for the validation of size-resolving PSC schemes used in large-scale chemistry-transport models.

[54] Acknowledgments. This work received funding mostly from the EU funded program GEMS and partly from the sixth framework program projects ALOMAR eARI, CNES and GEOMON. The quality of observations performed at ALOMAR is due to the efforts of the engineering and technical team. ECMWF is acknowledged for providing meteorological reanalysis. Finally, Max Frioud is acknowledged for his contribution and support. Andreas Stohl is also thanked for making available his wellestablished advection-dispersion model FLEXPART.

\section{References}

Althausen, D., D. Müller, A. Ansmann, U. Wandiger, H. Hube, E. Clauder, and S. Zörner (2000), Scanning 6-wavelength 11-channel aerosol lidar, Am. Meteorol. Soc., 17, 1469-1482.

Ansmann, A., M. Riebesell, and C. Weitkamp (1990), Measurement of atmospheric aerosol extinction profiles with a Raman lidar, Opt. Lett., 15, 746-748, doi:10.1364/OL.15.000746.

Ansmann, A., M. Riebesell, U. Wandinger, C. Weitkamp, E. Voss, W. Lahmann, and W. Michaelis (1992a), Combined Raman elastic-backscatter lidar for vertical profiling of moisture, aerosol extinction, backscatter, and lidar ratio, Appl. Phys. B, 55, 18-28, doi:10.1007/BF00348608.

Ansmann, A., U. Wandinger, M. Riebesell, C. Weitkamp, and W. Michaelis (1992b), Independent measurement of extinction and backscatter profiles in cirrus clouds by using a combined Raman elastic-backscatter lidar, Appl. Opt., 31, 7113-7131.

Baumgarten, G., J. Fiedler, and G. Von Cossart (2007), The size of noctilucent cloud particles above ALOMAR (69N, 16E): Optical modeling and method description, J. Adv. Space Res., doi:10.1016/j.asr.2007. 01.018.

Behrendt, A., and J. Reichardt (2000), Atmospheric temperature profiling in the presence of clouds with a pure rotational Raman Lidar by use of an interference-filter-based polychromator, Appl. Opt., 39, 1372-1378, doi:10.1364/AO.39.001372.

Beyerle, A., R. Neuber, and O. Schrems (1994), Multiwavelengths lidar measurements of stratospheric aerosols above Spitzenberg during winter 1992/1993, Geophys. Res. Lett., 21, 57-60, doi:10.1029/93GL02846.

Biele, J., A. Tsias, B. P. Luo, K. S. Carslaw, R. Neuber, G. Beyerle, and T. Peter (2001), Nonequilibrium coexistence of solid and liquid particles in Arctic stratospheric clouds, J. Geophys. Res., 106(D19), 22,991-23,007, doi:10.1029/2001JD900188.

Blum, U., F. Khosrawi, G. Baumgarten, K. Stebel, R. Müller, and K. H. Fricke (2006), Simultaneous lidar observations of a polar stratospheric cloud on the east and west sides of the Scandinavian mountains and microphysical box model simulations, Ann. Geophys., 24, 3267-3277.

Bohren, C. F., and D. R. Huffman (1983), Absorption and Scattering of Light by Small Particles, 530 pp., John Wiley, Hoboken, N. J.

Browell, E. V., C. F. Butler, S. Ismail, P. A. Robinette, A. F. Carter, N. S. Higdon, O. B. Toon, M. R. Schoeberl, and A. F. Tuck (1990), Airborne lidar observations in the wintertime Arctic stratosphere: Polar stratospheric clouds, Geophys. Res. Lett., 17, 385-388, doi:10.1029/ GL017i004p00385.

Carslaw, K. S., B. P. Luo, S. L. Clegg, T. Peter, P. Brimblecombe, and P. J. Crutzen (1994), Stratospheric aerosol growth and $\mathrm{HNO}_{3}$ and water uptake by liquid particles, Geophys. Res. Lett., 21, 2479-2482, doi:10.1029/94GL02799.

Carslaw, K. S., et al. (1998), Increased stratospheric ozone depletion due to mountain-induced atmospheric waves, Nature, 391, 675-678, doi:10.1038/35589.

Cooney, J., and M. Pina (1976), Laser radar measurements of atmospheric temperature profiles by use of Raman rotational backscatter, Appl. Opt., 15, 602-603, doi:10.1364/AO.15.000602.

David, C., S. Godin, G. Mégie, Y. Emery, and C. Flésia (1997), Physical state and composition of polar stratospheric clouds inferred from airborne lidar measurements during SESAME, J. Atmos. Chem., 27, 1-16, doi:10.1023/A:1005820407467.

David, C., S. Bekki, N. Berdunov, M. Marchand, and G. Mégie (2005), Classification and scales of Antarctic polar stratospheric clouds using wavelet decomposition, J. Atmos. Sol. Terr. Phys., 67, 293-300.

Del Guasta, M., M. Morandi, L. Stefanutti, B. Stein, and J. P. Wolf (1994), Derivation of Mount Pinatubo stratospheric aerosol mean size distribution by means of a multiwavelength lidar, Appl. Opt., 33, 5690-5697.
Deshler, T., B. Nardi, A. Adriani, F. Cairo, G. Hansen, F. Fierli, A. Hauchecorne, and L. Pulvirenti (2000), Determining the index of refraction of polar stratospheric clouds above Andoya $\left(69^{\circ} \mathrm{N}\right)$ by combing size-resolved concentration and optical scattering measurements, J. Geophys. Res., 105(D3), 3943-3953, doi:10.1029/1999JD900469.

Deshler, T., M. E. Hervig, D. J. Hofmann, J. M. Rosen, and J. B. Liley (2003a), Thirty years of in situ stratospheric aerosol size distribution measurements from Laramie, Wyoming $\left(41^{\circ} \mathrm{N}\right)$ using balloon-borne instruments, J. Geophys. Res., 108(D5), 4167, doi:10.1029/2002JD002514.

Deshler, T., et al. (2003b), Large nitric acid particles at the top of an Arctic stratospheric cloud, J. Geophys. Res., 108(D16), 4517, doi:10.1029/ 2003JD003479.

Dornbrack, A., and M. Leutbecher (2001), Relevance of mountain waves for the formation of polar stratospheric clouds over Scandinavia: A 20year climatology, J. Geophys. Res., 106(D2), 1583-1593, doi:10.1029/ 2000JD900250.

Dornbrack, A., M. Leutbecher, J. Reichardt, A. Behrendt, K. P. Muller, and G. Baumgarten (2001), Relevance of mountain wave cooling for the formation of polar stratospheric clouds over Scandinavia: Mesoscale dynamics and observations for January 1997, J. Geophys. Res., 106(D2), 1569-1581, doi:10.1029/2000JD900194.

Dornbrack, A., T. Birner, A. Fix, H. Flentje, A. Meister, H. Schmid, E. V. Browell, and M. J. Mahoney (2002), Evidence for inertia gravity waves forming polar stratospheric clouds over Scandinavia, J. Geophys. Res., 107(D20), 8287, doi:10.1029/2001JD000452.

Drdla, K. (1996), Application of a model of polar stratospheric clouds and heterogeneous chemistry, Ph.D. thesis, Univ. of Calif, Los Angeles.

Eckermann, S. D., A. Dornbrack, S. B. Vosper, H. Flentje, M. J. Mahoney, T. P. Bui, and K. S. Carslaw (2006), Mountain wave-induced polar stratospheric cloud forecasts for aircraft science flights during SOLVE/THESEO 2000, Weather Forecasting, 21(1), 42-68, doi:10.1175/WAF901.1.

Fahey, D., et al. (2001), The detection of large $\mathrm{HNO}_{3}$-containing particles in the winter Arctic stratosphere, Science, 291, 1026-1031, doi:10.1126 science. 1057265 .

Fierli, F., and A. Hauchecorne (2001), Analysis of polar stratospheric clouds using temperature and aerosols measured by the ALOMAR R/M/R lidar, J. Geophys. Res., 106(D20), 24,127-24,141, doi:10.1029/2001JD900062. Fueglistaler, S., S. Buss, B. P. Luo, H. Wernli, C. A. Hostetler, L. R. Poole, K. S. Carslaw, and T. Peter (2003), Detailed modeling of mountain wave PSC, Atmos. Chem. Phys. Discuss., 3, 253-299.

Goodman, J., O. B. Toon, R. F. Pueschel, K. G. Snetsinger, and S. Verma (1989), Antarctic stratospheric ice clouds, J. Geophys. Res., 94(D14), $16,449-16,458$.

Hanson, D., and K. Mauersberger (1988), Laboratory studies of the nitric acid trihydrate: Implications for the south polar stratosphere, Geophys. Res. Lett., 15, 855-858, doi:10.1029/GL015i008p00855.

Jumelet, J., S. Bekki, C. David, and P. Keckhut (2008), Statistical estimation of stratospheric particle size distribution by combining optical modelling and lidar scattering measurements, Atmos. Chem. Phys., 8, 1-14.

Klett, J. D. (1981), Stable analytical inversion solution for processing lidar returns, Appl. Opt., 20, 211-220.

Klett, J. D. (1985), Lidar inversion with variable backscatter/extinction ratios, Appl. Opt., 24, 1638-1643.

Knopf, D. A., T. Koop, B. P. Luo, U. G. Weers, and T. Peter (2002), Homogeneous nucleation of NAD and NAT in liquid stratospheric aerosols: Insufficient to explain denitrification, Atmos. Chem. Phys., 2, 207-214.

Krieger, U. K., J. C. Mössinger, B. P. Luo, U. Weers, and T. Peters (2000), Measurements of the refractive indices of $\mathrm{H}_{2} \mathrm{SO}_{4} / \mathrm{HNO}_{3} / \mathrm{H}_{2} \mathrm{O}$ solutions to stratospheric temperatures, Appl. Opt., 39, 3691-3703, doi:10.1364/ AO.39.003691.

Kühl, S., A. Dörnbrack, W. Wilms-Grabe, B. M. Sinnhuber, U. Platt, and T. Wagner (2004), Observational evidence of rapid chlorine activation by mountain waves above northern Scandinavia, J. Geophys. Res., 109, D22309, doi:10.1029/2004JD004797.

Lowe, D., A. R. MacKenzie, H. Schlager, C. Voigt, A. Dornbrack, M. J. Mahoney, and F. Cairo (2006), Liquid particle composition and heterogeneous reactions in a mountain wave polar stratospheric cloud, Atmos. Chem. Phys., 6, 3611-3623.

Luo, B., K. S. Carslaw, T. Peter, and S. L. Clegg (1995), Vapor pressures of $\mathrm{H}_{2} \mathrm{SO}_{4} / \mathrm{HNO}_{3} / \mathrm{HCl} / \mathrm{HBr} / \mathrm{H}_{2} \mathrm{O}$ solutions to low stratospheric temperatures, Geophys. Res. Lett., 22, 247-250, doi:10.1029/94GL02988.

Luo, B., U. K. Krieger, and T. Peter (1996), Densities and refractive indices of $\mathrm{H}_{2} \mathrm{SO}_{4} / \mathrm{HNO}_{3} / \mathrm{H}_{2} \mathrm{O}$ solutions to stratospheric temperatures, Geophys. Res. Lett., 23, 3707-3710, doi:10.1029/96GL03581.

Luo, B., C. Voigt, S. Fueglistaler, and T. Peter (2003), Extreme NAT supersaturations in mountain wave ice PSC: A clue to NAT formation, J. Geophys. Res., 108(D15), 4441, doi:10.1029/2002JD003104.

Mehrtens, H., U. von Zahn, F. Fierli, B. Nardi, and T. Deshler (1999), Type I PSC-particle properties: Measurements at ALOMAR 1995 to 1997, Geophys. Res. Lett., 26, 603-606, doi:10.1029/1999GL900027. 
Meilinger, S. K., T. Koop, B. P. Luo, T. Huthwelker, K. S. Carslaw, U. Kreiger, P. J. Crutzen, and T. Peter (1995), Size-dependent stratospheric droplet composition in lee wave temperature fluctuations and their potential role in PSC freezing, Geophys. Res. Lett., 22, 3031-3034, doi:10.1029/95GL03056.

Müller, D., U. Wandinger, D. Althausen, I. Mattis, and A. Ansmann (1998), Retrieval of physical particle properties from lidar observations of extinction and backscatter at multiple wavelengths, Appl. Opt., 37, 2260-2263, doi:10.1364/AO.37.002260.

Müller, H., and H. Quenzel (1985), Information content of multispectral lidar measurements with respect to the aerosol size distribution, Appl. Opt., 24, 648-654.

Nedeljkovic, D., A. Hauchecorne, and M. L. Chanin (1993), Rotational Raman lidar to measure the atmospheric temperature from the ground to $30 \mathrm{~km}$, IEEE Trans. Geosci. Remote Sens., 31, 90-101, doi:10.1109/ 36.210448 .

Peter, T. (1997), Microphysics and heterogeneous chemistry of polar stratospheric clouds, Annu. Rev. Phys. Chem., 48, 785-822, doi:10.1146/annurev. physchem.48.1.785.

Pinnick, R. G., J. M. Rosen, and D. J. Hofmann (1976), Stratospheric aerosol measurements III: Optical model calculations, J. Atmos. Sci., 33, 304-314, doi:10.1175/1520-0469(1976)033<0304:SAMIOM>2.0. $\mathrm{CO} ; 2$.

Popp, P. J., et al. (2001), Severe and extensive denitrification in the 1999 2000 Arctic winter stratosphere, Geophys. Res. Lett., 28, 2875-2878, doi:10.1029/2001GL013132.

Reichardt, J., S. Reichardt, P. Yang, and T. J. McGee (2002), Retrieval of polar stratospheric cloud microphysical properties from lidar measurements: Dependence on particle shape assumptions, J. Geophys. Res., 107(D20), 8282, doi:10.1029/2001JD001021.

Rex, M., et al. (1998), In situ measurements of stratospheric ozone depletion rates in the Arctic winter 1991/1992: A Lagrangian approach, J. Geophys. Res., 103(D5), 5843-5853, doi:10.1029/97JD03127.

Rex, M., et al. (1999), Chemical ozone loss in the Arctic winter 1994/95 as determined by the Match technique, J. Atmos. Chem., 32, 35-59.

Schöch, A. (2007), Thermal structure and gravity waves in the Arctic middle atmosphere above ALOMAR $\left(69.3^{\circ} \mathrm{N}, 16^{\circ} \mathrm{E}\right)$, Ph.D. thesis, LiebnizInst. für Atmos, Kühlungsborn, Germany.

Shibata, T., K. Shiraishi, H. Adashi, Y. Iwasaka, and M. Fujiwara (1999a), On the lidar-observed sandwich structure of polar stratospheric clouds (PSC): 1. Implications for the mixing state of the PSC particles, J. Geophys. Res., 104(D17), 21,603-21,611, doi:10.1029/1999JD900333.

Shibata, T., K. Shiraishi, H. Adashi, Y. Iwasaka, and M. Fujiwara (1999b), On the lidar-observed sandwich structure of polar stratospheric clouds (PSC): 2. Numerical simulations of externally mixed PSC particles, J. Geophys. Res., 104(D17), 21,613-21,619, doi:10.1029/1999JD900331.

Stohl, A., M. Hittenberger, and G. Wotawa (1998), Validation of the Lagrangian particle dispersion model FLEXPART against large scale tracer experiments, Atmos. Environ., 32, 4245-4264, doi:10.1016/S1352-2310(98) 00184-8

Tabazadeh, A., R. P. Turco, K. Drdla, and M. Z. Jacobson (1994), A study of type I polar stratospheric cloud formation, Geophys. Res. Lett., 21 , 1619-1622, doi:10.1029/94GL01368

Toon, O. B., A. Tabazadeh, E. V. Browell, and J. Jordan (2000), Analysis of lidar observations of Arctic polar stratospheric clouds during January 1989, J. Geophys. Res., 105(D16), 20,589-20,615, doi:10.1029/ 2000JD900144.

Tsias, A., et al. (1999), Aircraft lidar observation of an enhanced type Ia polar stratospheric cloud during APE-POLECAT, J. Geophys. Res., 104(D19), 23,961-23,969, doi:10.1029/1998JD100055.

Veselovskii, I., A. Kolgotin, V. Griaznov, D. Müller, U. Wandinger, and N. Whiteman (2002), Inversion with regularization for the retrieval of tropospheric aerosol parameters from multiwavelength lidar sounding, Appl. Opt., 41, 3685-3699, doi:10.1364/AO.41.003685.

Veselovskii, I., A. Kolgotin, V. Griaznov, D. Müller, K. Franke, and D. N. Whiteman (2004), Inversion of multiwavelength Raman lidar data for retrieval of bimodal aerosol size distribution, Appl. Opt., 43, 11801195, doi:10.1364/AO.43.001180.

Voigt, C., et al. (2000), Nitric acid trihydrate (NAT) in polar stratospheric clouds, Science, 290, 1756-1758, doi:10.1126/science.290.5497.1756.

Voigt, C., et al. (2005), Nitric acid trihydrate (NAT) formation at low NAT supersaturation in polar stratospheric clouds (PSC), Atmos. Chem. Phys., $5,1371-1380$.

von Zahn, U., G. von Cossart, J. Fiedler, H. Fricke, G. Nelke, G. Baumgarten, D. Rees, A. Hauchecorne, and K. Adolfsen (2000), The ALOMAR Rayleigh/Mie/Raman lidar: Objectives, configuration, and performance, Ann. Geophys., 18, 815-833, doi:10.1007/s005850000210.

Wallenhauer, S. (1998), Bestimmung spektraler Streukoeffizienten des atmosphärischen Aerosols aus Lidarmessungen, diploma thesis, 52 pp., Univ. Leipzig, Leipzig, Germany.

World Meteorological Organization (2006), Assessment of stratospheric aerosol properties, WCRP-124, Geneva.

World Meteorological Organization (2007), Scientific assessment of ozone depletion: 2006, Global Ozone Res. and Monit. Project Rep. 50, 572 pp., Geneva.

G. Baumgarten, Leibniz-Institut für Atmosphärenphysik, D-18225 Kühlungsborn, Germany. (baumgarten@iap-kborn.de)

S. Bekki, C. David, J. Jumelet, and P. Keckhut, Service d'Aéronomie, IPSL, UPMC, CNRS, 4 place Jussieu, Tour 45-46, F-75252 Paris, France. (slimane.bekki@aero.jussieu.fr; christine.david@aero.jussieu.fr; julien. jumelet@aero.jussieu.fr; philippe.keckhut@aerov.jussieu.fr) 